\title{
On-chip two-phase cooling of datacenters: Cooling system and energy recovery evaluation
}

\author{
Jackson Braz Marcinichen*, Jonathan Albert Olivier, John Richard Thome \\ Laboratory of Heat and Mass Transfer (LTCM), Faculty of Engineering (STI), École Polytechnique Fédérale de Lausanne (EPFL), Station 9, CH-1015 Lausanne, Switzerland
}

\section{A R T I C L E I N F O}

\section{Article history:}

Received 5 May 2011

Accepted 5 December 2011

Available online $\mathrm{xxx}$

\section{Keywords:}

Datacenter

Microprocessor

Hybrid two-phase cooling cycle

Micro-evaporator

Power plant

Energy recovery

\begin{abstract}
A B S T R A C T
Cooling of datacenters is estimated to have an annual electricity cost of 1.4 billion dollars in the United States and 3.6 billion dollars worldwide. Currently, refrigerated air is the most widely used means of cooling datacenter's servers, which typically represents $40-45 \%$ of the total energy consumed in a datacenter. Based on the above issues, thermal designers of datacenters and server manufacturers now seem to agree that there is an immediate need to improve the server cooling process. The goal of the present study is to propose and simulate the performance of a novel hybrid two-phase cooling cycle with micro-evaporator elements (multi-microchannel evaporators) for direct cooling of the chips and auxiliary electronics on blade server boards (savings in energy consumption of over $60 \%$ are expected). Different working fluids were considered, namely water, HFC134a and a new, more environmentally friendly, refrigerant HFO1234ze. The results so far demonstrated that the pumping power consumption is on the order of 5 times higher for the water-cooled cycle. Additionally, a case study considering the hybrid cooling cycle applied on a datacenter and exploring the application of energy recovered in the condenser on a feedwater heater of a coal power plant was also investigated (modern datacenters require the dissipation of 5-15 MW of heat). Aspects such as minimization of energy consumption and $\mathrm{CO}_{2}$ footprint and maximization of energy recovery (exergetic efficiency) and power plant efficiency are investigated.
\end{abstract}

(c) 2011 Elsevier Ltd. All rights reserved.

\section{Introduction}

Reduction of primary energy consumption is strongly required to mitigate global warming. To achieve this objective, the use of waste heat thermal energy or renewable energy should be increased in energy conversion processes, reducing fossil fuel consumption. Under the current efficiency trends, the energy usage of datacenters in the US is estimated to be more than 100 billion kWh by 2011, which represents an annual cost of approximately $\$ 7.4$ billion [15]. With the introduction of a proposed carbon tax in the US [23], the annual costs could become as high as $\$ 8.8$ billion by 2012, increasing annually.

Cooling of datacenters can represent up to $45 \%$ [22] of this total consumption using current cooling technologies (air cooling). In the US, this relates to an estimated 45 billion kWh usage by 2011 with an annual cost of $\$ 3.3$ billion, or $\$ 4$ billion with the inclusion of carbon tax... just for cooling. A problem with a datacenter is that all the energy consumed is converted into heat, which with current

\footnotetext{
* Corresponding author. Tel.: +41 21693 5894; fax: +41 216935960 .

E-mail address: jackson.marcinichen@epfl.ch (J.B. Marcinichen).
}

technologies is rejected as waste into the atmosphere. Therefore, reusing this waste heat can potentially not only reduce the overall operating costs, but also the carbon footprint of the datacenter.

Most datacenters make use of air cooling technologies to ensure the correct running of the servers contained within. The limits of air cooling, however, are being approached due to the performance increase in microprocessors, which will have heat fluxes in the order of $100 \mathrm{~W} / \mathrm{cm}^{2}$. This trend is shown in Fig. 1 with the red dots obtained from [49]. It was shown that air has a maximum heat removal capacity of about $37 \mathrm{~W} / \mathrm{cm}^{2}$ [47]. The problem is made worse with servers being more densely packed, such as the blade centers of IBM [20], which could see racks generating in excess of $60 \mathrm{~kW}$ of heat. Today's datacenters are designed for cooling capacities in the order of $10-15 \mathrm{~kW}$ per rack [48]. Hence, if datacenters want to take advantage of increasing computer power having a smaller surface footprint, other solutions to air cooling are required.

One solution is to make use of on-chip cooling, where the primary coolant, a liquid or refrigerant, is brought right up to the main processor and auxiliary electronics and is used as a replacement to air. Recent publications show the development of primarily four competing technologies for the cooling of chips: microchannel 


\begin{tabular}{|c|c|c|c|}
\hline \multicolumn{2}{|c|}{ Nomenclature } & \multicolumn{2}{|c|}{ Acronyms } \\
\hline & & $\mathrm{AE}$ & auxiliary electronics \\
\hline & & $\mathrm{CHF}$ & critical heat flux $\left[\mathrm{Wcm}^{-2}\right]$ \\
\hline \multicolumn{2}{|l|}{ Roman } & COP & coefficient of performance [-] \\
\hline & rate of exergy destruction due to irreversibilities & CPU & central processing unit \\
\hline & within the control volume, W & EEV & electric expansion valve \\
\hline$\dot{e}_{\mathrm{fi}}, \dot{e}_{\mathrm{fe}}$ & inlet and outlet flow exergies, $\mathrm{J} / \mathrm{kg}$ & $i \mathrm{HE} x$ & internal heat exchanger \\
\hline$\dot{m}_{i}, \dot{m}_{e}$ & inlet and outlet mass flow rate, $\mathrm{kg} / \mathrm{s}$ & LA & liquid accumulator \\
\hline$Q_{\mathrm{AE}}$ & heat load associated with the auxiliary electronics, W & LP & liquid pump \\
\hline$Q_{\text {cond }}$ & heat transfer rate at the condenser, $\mathrm{W}$ & LPR & low pressure receiver \\
\hline$\dot{Q}_{j}$ & heat transfer rate, $\mathrm{W}$ & ME & micro-evaporator \\
\hline$Q_{\mathrm{ME}}$ & heat load associated with the microprocessor, $\mathrm{W}$ & $\mathrm{MP}_{\mathrm{AE}}$ & microchannel cold plate applied on auxiliary \\
\hline \multicolumn{4}{|c|}{ heat transfer rate at the subcooler, $\mathrm{W}$} \\
\hline & instantaneous temperature, ${ }^{\circ} \mathrm{C}$ & PCV & pressure control valve \\
\hline & dead state temperature, ${ }^{\circ} \mathrm{C}$ & SP_W & single-phase liquid water in the $\mathrm{ME}$ \\
\hline$\dot{W}_{\mathrm{CV}}$ & energy transfer rate by work, W & TCV & temperature control valve \\
\hline \multirow{3}{*}{\multicolumn{2}{|c|}{$\begin{array}{l}W_{\text {LP_or_vc pumping power consumption of the driver, which can }} \\
\text { be the liquid pump or the vapor compressor, } \mathrm{W}\end{array}$}} & & two-phase \\
\hline & & \multirow{2}{*}{\multicolumn{2}{|c|}{$\begin{array}{l}\text { TP_HFC134a two-phase HFC134a in the ME } \\
\text { TP_HFO1234ze two-phase HFO1234ze in the ME }\end{array}$}} \\
\hline & & & \\
\hline \multicolumn{2}{|c|}{ Subscripts } & VC & vapor compressor \\
\hline $\begin{array}{l}\text { cond } \\
\text { sub }\end{array}$ & $\begin{array}{l}\text { condenser } \\
\text { subcooler }\end{array}$ & VSC & variable speed compressor \\
\hline
\end{tabular}

single-phase flow, porous media flow, jet impingement cooling and microchannel two-phase flow [1]. [25] showed that the use of such new technology for cooling of chips could produce savings in energy consumption of over 60\% [1] highlighted that the most promising of the four technologies was microchannel two-phase cooling.

Single-phase microchannel chip cooling has its apparent advantage in that it is relatively easy to use. This technology is currently being used in the recently started Aquasar [16], which is an IBM blade center converted to make use of a water-cooled cycle. However, water has many disadvantages in that it requires a high pumping power to keep temperature gradients on the microprocessor to within acceptable limits. Furthermore, water presents a problem with its high freezing point, microbe formation, corrosive properties, electrical conductivity and erosive nature due to high fluid velocities.

Two-phase microchannel flow takes advantage of the latent heat of the fluid, which is much more effective in removing heat than when using the sensible heat of a single-phase fluid. The latent

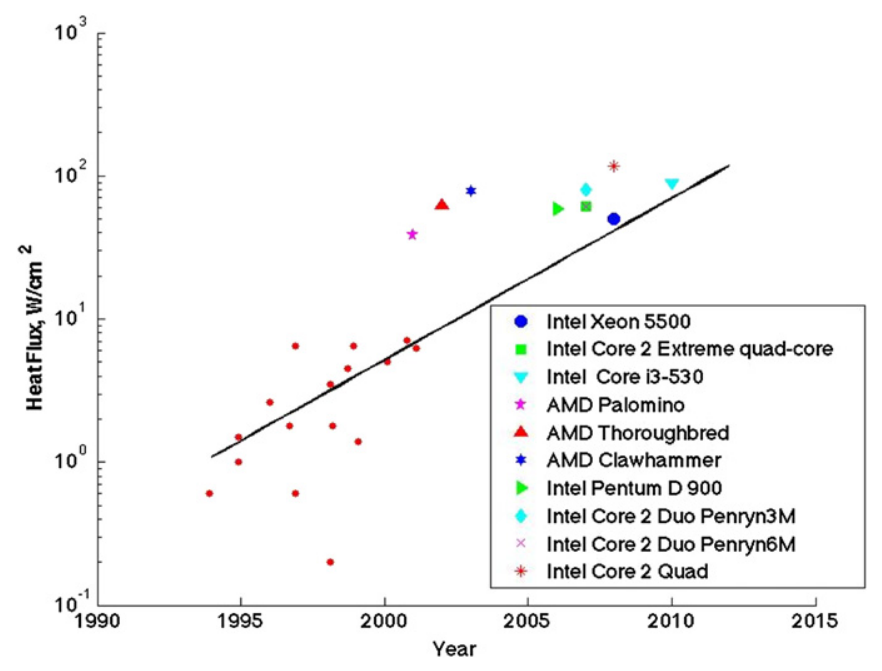

Fig. 1. Heat flux trend of commercial processors. Red markers from [49]. heat also implies that chip temperatures are much more uniform. It has been shown that heat fluxes as high as $300 \mathrm{~W} / \mathrm{cm}^{2}$ [40] can be achieved using a two-phase refrigerant while maintaining chip temperatures below their critical value. Heat fluxes of $1000 \mathrm{~W} / \mathrm{cm}^{2}$ have been reached using refrigerants [24], although this was under subcooled boiling with mass fluxes and pressure drops being an order of magnitude higher than microchannel two-phase boiling. It was further shown that heat fluxes of $180 \mathrm{~W} / \mathrm{cm}^{2}$ can be removed with a saturation temperature as high as $60^{\circ} \mathrm{C}$, while maintaining the chip temperature below $85{ }^{\circ} \mathrm{C}$ [27]. A refrigerant has the advantage of being a dielectric fluid with a long successful history in industrial applications, is inert to most engineering materials, readily available and relatively inexpensive. New refrigerants also have a negligible impact on the environment.

The main advantage of making use of on-chip cooling for the cooling of datacenters is that the heat gained from cooling the chips can be easily reused elsewhere. This is because the heat removal process is local to the chip and the fact that the heat carrying capacity of the refrigerant is much higher than that of air, thus minimizing any losses to the environment. The opportunity thus exists to reuse the datacenter's waste heat in secondary applications instead of being disposed of into the atmosphere. This not only has the potential to reduce datacenter energy costs, but also to reduce its carbon footprint and hence, its environmental impact.

A problem with recovering the heat of the datacenter is not in the quantity of heat available, but rather in the quality of heat. Currently, heat is being ejected into the atmosphere at temperatures of about $40{ }^{\circ} \mathrm{C}$ when using traditional air cooling methods. This is because chip temperatures are being cooled at $15-20^{\circ} \mathrm{C}$. Due to the effective cooling of chips when using on-chip cooling, fluid approach temperatures of about $60^{\circ} \mathrm{C}$ can be realized, while removing high heat fluxes and keeping chip temperatures below $85^{\circ} \mathrm{C}$ [27]. Although the temperature, and hence the quality of the heat is higher, the applications for using this heat are still limited.

Making use of a vapor compression cooling cycle, where temperatures in excess of $90{ }^{\circ} \mathrm{C}$ can be realized, can increase the quality of the heat, i.e., the exergy, even further. Exergy of a system is the maximum useful energy that brings the system into the equilibrium with its surroundings. After the system and surroundings reach equilibrium, the exergy is zero. The potential 
for this kind of heat not only increases the number of applications that can use it, but also increases its value. Vapor compression cooling cycles for computer chips have been demonstrated successfully [34] and [55], although it was focused on a small system where the recovery of heat was not of concern.

In this context, the objective of the present study is primarily to propose and analyze potential two-phase cooling cycles able to maintain the temperature of the chip below its upper operating limit (about $85{ }^{\circ} \mathrm{C}$ ) and to recover energy from the cycle's condenser for reuse, such as for heating a building, residence, hospital, district heating, etc. To do this, an in-house integrated simulation code was developed which has the capability to design the components and determine the performance of a hybrid cooling cycle (liquid pump or vapor compressor as the driver of the working fluid) under steady state conditions and for different working fluids. The code is also able to evaluate the performance of the cooling cycles for single-phase and two-phase flow in the micro-evaporators.

The new refrigerant HFO1234ze of Honeywell Inc. is considered here as a potential substitute of HFC134a. This fluid has a "Global Warning Potential" of only 6 against 1410 of HFC134a, i.e., it is considered as an immediate/future replacement for HFC134a. Both HFC134a and HFO1234ze are dielectric fluids and thus compatible with electronics. HFC134a is currently the most widely used refrigerant for refrigeration and air conditioning systems.

Secondly, a case study is developed to demonstrate the overall potential savings that can be made by implementing two-phase on-chip cooling within a datacenter. The investigation will take into account the benefits over the datacenter and a secondary application of the waste heat. For this paper a coal fired thermal power plant will be analysed since more than $41 \%$ of the world's energy is produced from these types of plants [57]. This plant was also chosen as it produces most of the greenhouse gases, with any potential improvements in efficiency translating to savings for both the power plant and the datacenter.

\section{Literature review}

[18] have proposed a pumped liquid multiphase cooling system (PLMC) to cool microprocessors and microcontrollers of high-end devices such as computers, telecommunications switches, highenergy laser arrays and high-power radars. According to them, their system could handle applications with $100 \mathrm{~W}$ heat loads (single computer chip) as well as applications with short time periods of $\mathrm{kW}$ heat loads (radar). Their PLMC consists of a liquid pump, a high performance cold plate (evaporator) and a condenser with a low acoustic noise air mover to dissipate the heat in the ambient air. A comparison between a single-phase liquid loop (water) and the system proposed with HFC134a was made for a $200 \mathrm{~W}$ heat load. The HFC134a system had a mass flow rate, a pumping power and a condenser size that were 4.6, 10 and 2 times smaller than the water-cooled system. The coolant temperature rise was $10{ }^{\circ} \mathrm{C}$ for the water but negligible for HFC134a. They emphasized the significant benefits from efficiency, size and weight that were provided with the PLMC solution.

[34] designed and built a small-scale refrigeration system applicable for a notebook computer. The system included a minicompressor, a microchannel condenser, a microchannel evaporator and a capillary tube as the throttling device and is considered to be the first refrigeration system developed that can fit within the tight confines of a notebook and operate with high refrigeration efficiencies. HC600a (isobutane) was the working fluid, chosen from an evaluation of 40 candidate refrigerants. According to them, HC600a presented the best efficiency at a low pressure ratio and was readily available. Although it is flammable the system only required a very small charge (a few milliliters). For a baseline operating condition, when the evaporator and condenser temperatures and the heat load were $50{ }^{\circ} \mathrm{C}, 90{ }^{\circ} \mathrm{C}$ and $50 \mathrm{~W}$, the coefficient of performance (COP) obtained was 2.25. The COP reached 3.70 when the evaporator and condenser temperatures increased and decreased by $10{ }^{\circ} \mathrm{C}$ from the baseline conditions and the heat load was reduced to $44 \mathrm{~W}$. The small-scale refrigeration system achieved 25-30\% of the Carnot efficiency (ideal COP for a Carnot cycle), values comparable with those obtained in today's household refrigerators.

[55] designed, built and evaluated the performance of a miniaturescale refrigeration system (MSRS) suitable for electronics cooling applications. Their MSRS had the following components: a commercial small-scale compressor, a microchannel condenser, a manual needle valve as the expansion device, a cold plate microchannel evaporator, a heat spreader and two compressor cooling fans. A suction accumulator to avoid liquid flow to the compressor, an oil filter to return oil to the compressor and guarantee good lubrication, and heat sources to simulate the chips were also installed. HFC134a was the working fluid. System performance measurements were conducted at evaporator temperatures from $10{ }^{\circ} \mathrm{C}$ to $20{ }^{\circ} \mathrm{C}$ and condenser temperatures from $40^{\circ} \mathrm{C}$ to $60{ }^{\circ} \mathrm{C}$. The cooling capacity of the system varied from $121 \mathrm{~W}$ to $268 \mathrm{~W}$ with a COP of $1.9-3.2$ at pressure ratios of 1.9-3.2. Their MSRS was able to dissipate CPU heat fluxes of approximately $40-75 \mathrm{~W} / \mathrm{cm}^{2}$ and keep the junction temperature below $85^{\circ} \mathrm{C}$ for a chip size of $1.9 \mathrm{~cm}^{2}$. It was concluded that a new compressor design for electronics cooling applications was needed to achieve better performance of the system (the most significant losses occurred in the compressor, which was not designed for the operating conditions of electronics cooling). It was also recommended to study the development of an automatic expansion device and a suitable control strategy for the MSRS.

[52] surveyed the advances in thermal modeling for flow boiling of low pressure refrigerants in multi-microchannel evaporators for cooling of microprocessors. According to them, multi-microchannel evaporators hold promise to replace the actual air cooling systems and can compete with water cooling to remove high heat fluxes, higher than $300 \mathrm{~W} / \mathrm{cm}^{2}$, while maintaining the chip safely below its maximum working temperature, providing a nearly uniform chip base temperature [2] and minimizing energy consumption. Variables such as critical heat fluxes, flow boiling heat transfer coefficients and two-phase friction factors were evaluated and characterized as important design parameters to the microevaporator for high heat flux applications.

[53] simulated two-phase cooling elements for microprocessors with micro-evaporation. Heat fluxes of $50 \mathrm{~W} / \mathrm{cm}^{2}$ and $150 \mathrm{~W} / \mathrm{cm}^{2}$ in a micro-evaporator with channels $75 \mu \mathrm{m}$ wide, $680 \mu \mathrm{m}$ high and $6 \mathrm{~mm}$ long with $100 \mu \mathrm{m}$ thick fins were simulated for flow boiling. The size of the chip was assumed to be $12 \mathrm{~mm}$ by $18 \mathrm{~mm}$ and the micro-evaporator was considered with the fluid inlet at the centerline of the chip and outlets at both sides, i.e., a split flow design to reduce the pressure drop and increase the critical heat flux. Results of pumping power, critical heat flux, and junction and fluid temperatures were generated for HFC134a at an inlet saturation temperature of $55{ }^{\circ} \mathrm{C}$ (chosen to allow for heat recovery). The following conclusions were reached: i) the influence of mass flux on the fluid, chip and wall temperatures was small, ii) for the heat flux of $150 \mathrm{~W} / \mathrm{cm}^{2}$, the chip temperature was $70^{\circ} \mathrm{C}$ or less, i.e., well below its operational limit of $85{ }^{\circ} \mathrm{C}$, iii) the junction-to-fluid temperature difference was only $15 \mathrm{~K}$ for the heat flux of $150 \mathrm{~W} / \mathrm{cm}^{2}$, which is lower than that with liquid cooling systems, iv) the fluid working temperature could still be raised by $10 \mathrm{~K}$ to a junction temperature of $80{ }^{\circ} \mathrm{C}$ while rejecting heat at $65{ }^{\circ} \mathrm{C}$ for reuse, and v) the critical heat flux increased with the mass flux and the lower limit was about $150 \mathrm{~W} / \mathrm{cm}^{2}$ for $250 \mathrm{~kg} / \mathrm{m}^{2} \mathrm{~s}$. The channel 
width had a significant effect on the wall and junction temperatures, and there was a turning point at about $100 \mu \mathrm{m}$ when considering $1000 \mathrm{~kg} / \mathrm{m}^{2} \mathrm{~s}$ of mass flux and $150 \mathrm{~W} / \mathrm{cm}^{2}$ of base heat flux, at which these temperatures reached a minimum. For the same mass flux and base heat flux, the reduction of channel width also reduced the energy consumption to drive the flow (pumping power).

From a system viewpoint [53], showed an approximate comparison of performances of liquid water cooling versus twophase cooling. For the same pumping power consumption to drive the fluids, two-phase cooling allowed the chip to operate about $13 \mathrm{~K}$ cooler than water cooling or it could operate at the same junction temperature but consume less pumping power using a lower refrigerant flow rate. The two-phase cooling system appeared to be more energy-efficient than classical air cooling or direct liquid cooling systems while also exhausting the heat at higher reusable temperatures. Regarding the choice between a pump and a compressor as the driver for a micro-evaporation heat sink system, they emphasized that the choice depends on the economic value of the reused energy. The system with a compressor is ideal for energy reuse because of the higher heat rejection temperature; however the additional energy consumed by the compressor compared to the pump has to be justified by the reuse application.

[31] evaluated the performance of a multi-microchannel copper heat sink with respect to critical heat flux (CHF) and two-phase pressure drop. A heat sink with 29 parallel channels $(199 \mu \mathrm{m}$ wide and $756 \mu \mathrm{m}$ deep) was tested experimentally with a split flow system with one central inlet at the middle of the channels and two outlets at either end. Three working fluids were tested (HFC134a, HFC236fa and HFC245fa) and also the parametric effects of mass velocity, saturation temperature and inlet temperature. The analysis of their results showed that a significantly higher CHF was obtainable with the split flow system compared to the single inletsingle outlet system [41], providing also a much lower pressure drop. For the same mass velocity, the increase in CHF exceeded $80 \%$ for all working fluids evaluated due to the shorter heated length of a split system design. For the same total refrigerant mass flow rate, an increase of $24 \%$ for HFC134a and $43 \%$ for HFC236fa were obtained (no comparable data were available for HFC245fa). They concluded that the split flow system had the benefit of much larger $\mathrm{CHF}$ values with reduced pressure drops and further developments in the design of split flow system could yield an interesting energetic solution for cooling of computer chips.

[58] developed a steady state model of a refrigeration system for high heat flux electronics cooling. The refrigeration system proposed consists of multiple evaporators (microchannel technology), liquid accumulator with an integrated heater, variable speed compressor, condenser and electric expansion valves (EEV). To obtain more efficient heat transfer and higher critical heat flux, the evaporators were considered to operate only with two-phase flow. To guarantee the safe operation of the refrigeration system the authors considered the presence of an integrated heateraccumulator to fully evaporate the two-phase flow coming out of the evaporator, which naturally represents a decrease of the cycle COP. A parametric study to evaluate the effects of external inputs on the system performance (secondary fluid temperature in the condenser, evaporator heat load, compressor speed, EEV percentage opening and heat supplied to the accumulator) and a Pareto optimization to find the optimal system operating conditions were also developed. A heat load of $1500 \mathrm{~W}$ and $2500 \mathrm{~W}$, which represent respectively a heat flux of $94 \mathrm{~kW} / \mathrm{m}^{2}$ and $156.6 \mathrm{~kW} / \mathrm{m}^{2}$ were considered. The main points observed were: i) the system COP can be improved without compromising the critical heat flux when handling higher heat flux, ii) higher critical heat fluxes are achieved with a smaller EEV opening and higher heat input supplied to the accumulator and iii) a trade-off between the system COP and CHF is necessary to prevent the device burnout, i.e., imposed heat flux must be lower than the CHF considering a safety margin. Finally, they presented a preliminary validation of the model with initial experimental data showing a satisfactory prediction ability of the model. The authors do not mention anything about the geometry assumed for the evaporators.

The present study is a continuation of the earlier study developed by [28]. They proposed a two-phase cooling cycle considering a liquid pump as the driver of the fluids, a micro-evaporator for cooling the chip and its auxiliary electronics, and a microfin tubein-tube condenser for heat recovery. A standard length $(30 \mathrm{~cm})$ and internal diameter ( $3 \mathrm{~mm}$ ) was defined for the pipes joining the components, which were assumed to be only straight and horizontal, i.e., the effects of bends and static height difference between components and pipes were ignored. The performance of the cooling cycle considered 3 different working fluids; HFC134a, HFO1234ze and water (in an analogous single-phase cooling cycle). The results showed that for a design of the cooling cycle so that the total pressure drop is about 1 bar, the liquid water cooling cycle had a pumping power consumption 16.5 times that obtained for the two-phase HFC134a cooling cycle. When comparing with the HFO1234ze cooling cycle, which showed a total pressure drop of 1.2 bar, the difference drops to 13.2 times. These results can be considered a differential when compared with demonstration projects, such as that for the new supercomputer called AQUASAR [16], which considers the implementation of a liquid water cooling cycle on a rack cabinet with power consumption of around $10 \mathrm{~kW}$. It is important to mention that the simulations presented were considered as a benchmark and that the energetic comparison should be applied to an actual server's specifications, which is the subject that is considered here. Additionally, a case study considering a vapor compression and a liquid pumping cooling systems applied on a datacenter and exploring the application of energy recovered in the condenser on a feedwater heater of a coal power plant will be presented. Aspects such as the minimization of energy consumption and $\mathrm{CO}_{2}$ footprint and the maximization of energy recovery and power plant efficiency are investigated.

\section{Hybrid two-phase cooling cycle}

Fig. 2 depicts the proposed hybrid two-phase cooling cycle, i.e., a multi-purpose cooling cycle able to interchange the cycle driven by a liquid pump or a vapor compressor. The change of cycle would be accomplished by means of shut-off valves 1 to 7 (SOV). The choice of the cooling cycle would depend on the demand for heat recovery, or whether cycle maintenance is required (repair of the compressor or pump with one mode as a backup to the other mode). The microprocessors cannot operate without cooling and thus the interchangeability of the cycles represents a safety mechanism in case of failure of the pump or compressor. The cons of the hybrid cycle would mainly be the higher initial cost but certainly the advantages gained (system online reliability, controllability, cycle interchangeability and flexibility in heat recovery) may prove to justify this. Furthermore, this hybrid cycle represents a plug-and-play option where any one of the three cycles can be installed based on the particular application to standardize the design, thus minimizing engineering costs.

The goal is to control the chip temperature to a pre-established level by controlling the inlet conditions of the micro-evaporator (pressure, subcooling and mass flow rate). It is also imperative to keep the micro-evaporator (ME) outlet vapor quality below that of the critical vapor quality, which is associated with the critical heat flux. The critical vapor quality is determined from the critical heat 


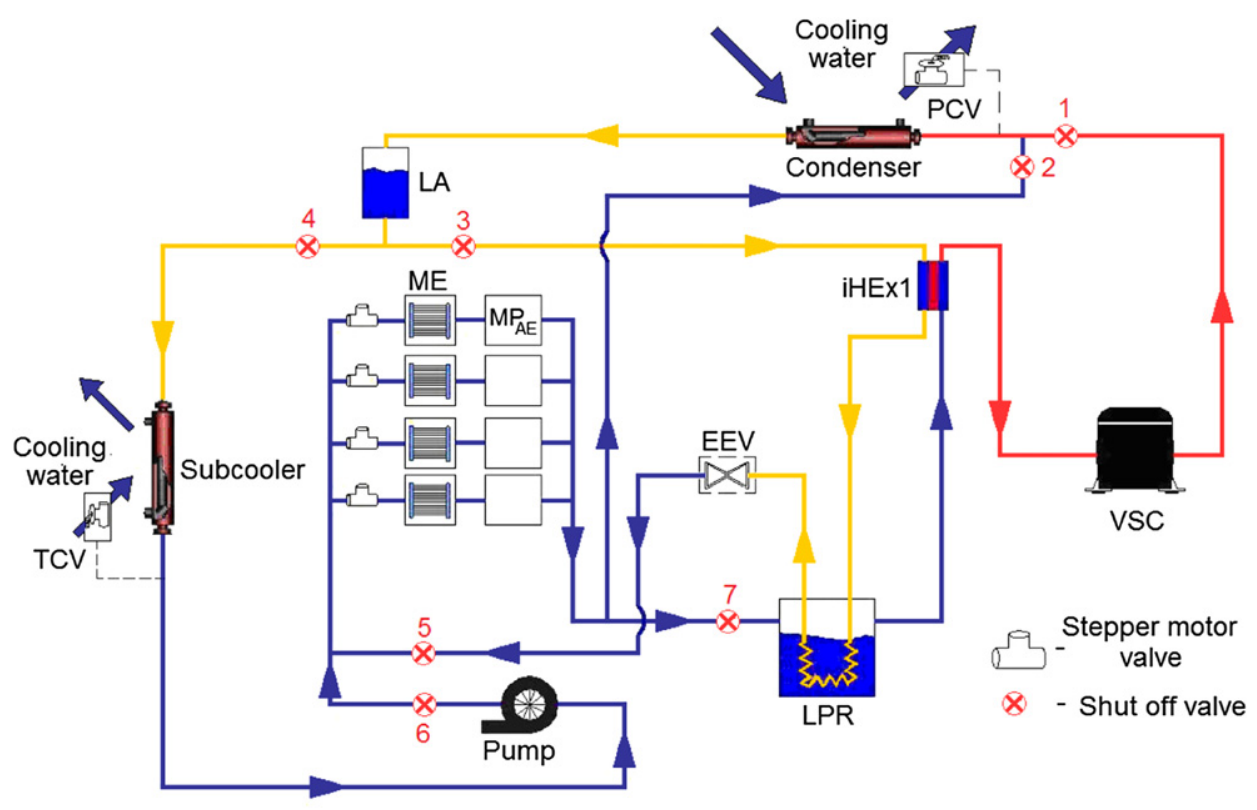

Fig. 2. Hybrid two-phase cooling cycle.

flux [39] and an energy balance on the ME. Due to this limitation, additional latent heat is available for further evaporation, which can be used by other low heat flux generating components in the blade server.

Another parameter that must be controlled is the condensing pressure (condensing temperature). The aim, during the winter, is to recover the energy dissipated by the refrigerant in the condenser to heat buildings, residences, district heating, etc. In order to accomplish this, the idea is to use a variable speed compressor (VSC) and an electric expansion valve (EEV), as will be discussed below.

Fig. 3 depicts the two-phase cooling cycle where the flow rate is controlled by a liquid pump. The components considered and their main functions are presented below:

a) Variable speed liquid pump: controls the mass flow rate circulating in the system.

b) Stepper motor valve: controls the liquid flow rate to control the outlet vapor quality in each micro-evaporator $(0 \%-100 \%)$. It

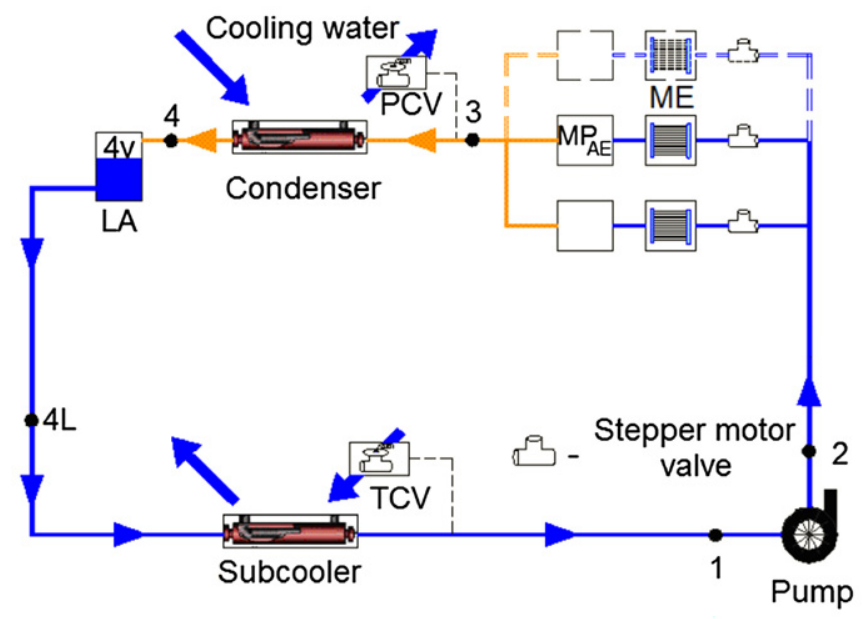

Fig. 3. Schematic of the liquid pump cooling cycle. avoids potential problems of mal-distribution in each ME line due to non-uniform heat load on the microprocessors and bad pipeline designs. Preliminary experimental evaluation can be found in [30]; where one SMV controlling the mixture (junction of piping) outlet vapor quality of two MEs proved to be feasible and efficient

c) Micro-evaporator (ME): transfers the heat generated by the microprocessor to the refrigerant.

d) Microchannel cold plate for auxiliary electronics $\left(\mathrm{MP}_{\mathrm{AE}}\right)$ : additional component used to cool the auxiliary electronics using the remaining latent heat, which is available due to the limitations enforced on the micro-evaporator.

e) Pressure control valve (PCV): controls the condensing pressure.

f) Condenser: counter-flow tube-in-tube exchanger.

g) Liquid accumulator (LA): guarantees that there is only saturated liquid at the subcooler inlet, independent of changes in thermal load.

h) Temperature control valve (TCV): controls the subcooling at the inlet of liquid pump.

This cycle is characterized in having a low vapor quality at the ME outlet, a low condensing temperature and a high overall

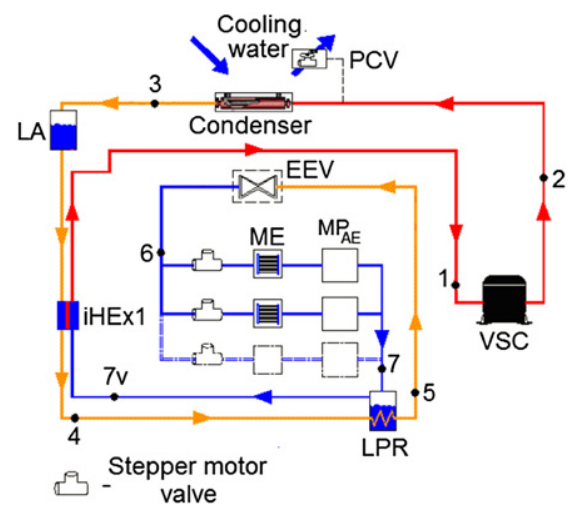

Fig. 4. Schematic of the vapor compression cooling cycle. 
efficiency. This is a good operating option when the energy dissipated in the condenser is not recovered, typically during the summer season. However, the heat can still be recovered if there is an appropriate demand for low quality heat (low exergy).

Fig. 4 shows a two-phase cooling cycle where a vapor compressor is the driver of the working fluid. The components considered and their main functions are:

a) Variable speed compressor: controls the ME inlet pressure and consequently the level of inlet subcooling.

b) Pressure control valve (PCV): controls the condensing pressure.

c) Condenser: counter-flow tube-in-tube exchanger.

d) Liquid accumulator: guarantees that there is only saturated liquid at the internal heat exchanger (iHEx1) inlet.

e) Internal heat exchanger liquid line/suction line (iHEx1): increases the performance of the cooling system.

f) Electric expansion valve (EEV): controls the low pressure receiver level.

g) Low pressure receiver (LPR): this component can be seen as a second internal heat exchanger liquid line/suction line, which increases the EEV inlet subcooling and allows an overfeed to the ME since the ME outlet returns to this receiver.

h) Stepper motor valve: controls the liquid flow rate to control the outlet vapor quality in each micro-evaporator (0\%-100\%).

i) Micro-evaporator (ME): transfers the heat away from the microprocessor.

j) Microchannel cold plate for auxiliary electronics (MPAE): cools the auxiliary electronics.

This cycle is characterized by a high condensing temperature (high heat recovery potential), a high range of controllability of the ME inlet subcooling (characteristic of systems with VSC and EEV), and potentially a medium overall efficiency when compared with the liquid pumping cooling cycle. This is a good operating option when the energy dissipated in the condenser is recovered for other use, typically during the winter season when considering a district heating application or the entire year for a feedwater heater of a coal power plant (high exergy).

It is worth mentioning that the applicability of these cooling cycles is not restricted to only one microprocessor but can be applied to blade servers and clusters, which may have up to 64 blades per rack cabinet. Each blade, such as that shown in Fig. 5, can have two (or more) microprocessors with a heat generation capacity higher than $150 \mathrm{~W}$. If the auxiliary electronics (memories, $D C / D C$, etc.) on the blade are included, the total heat generation per blade can be higher than $300 \mathrm{~W}$. Thus, the microchannel cold plate $\left(\mathrm{MP}_{\mathrm{AE}}\right)$ described in the cooling cycles has the function to cool the auxiliary electronics that can represent about $60 \%$ of the total heat

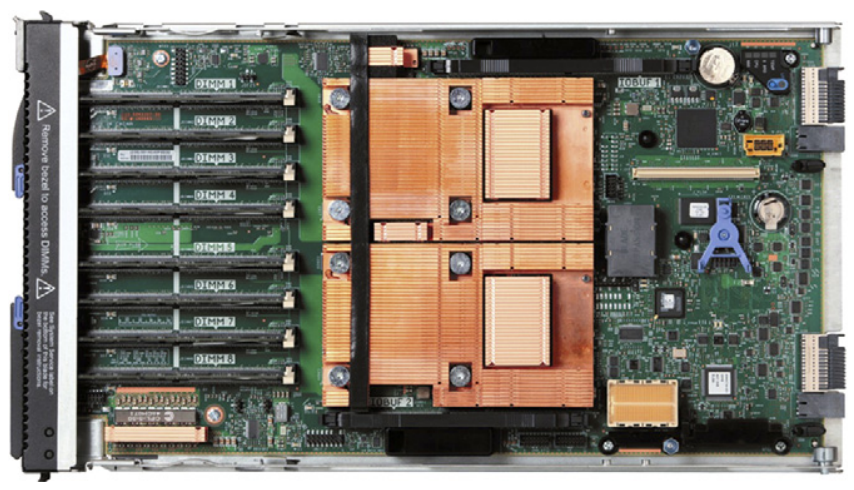

Fig. 5. Typical blade with two microprocessors and a heat generation capacity higher than $300 \mathrm{~W}$. load on the blade, but will have a larger surface area compared to the CPU and thus a lower heat flux.

Finally, when considering an entire rack, a very sizable heat load is generated, which represents a good opportunity to recover the heat rejected. In this case, reuse of the heat removed from the blades for a secondary application will greatly reduce the $\mathrm{CO}_{2}$ footprint of the system. For example, if we consider a datacenter with 50 vertical racks, where each rack has 64 blades and each blade dissipates $300 \mathrm{~W}$, the total potential heat to be recovered will be $0.96 \mathrm{MW}$. Such a heat recovery system requires a secondary heat transfer fluid to pass through all the condensers (either water or a refrigerant) and then transport the heat to its destination. Additional information on such cycles can be found in the previous work of the [29].

\section{Simulation code}

An in-house two-phase cooling cycle simulation code was developed to design and evaluate the performance of the liquid pump and vapor compressor cooling cycles under steady state conditions. The simulation code is able to design the condenser and subcooler, to evaluate the performance of the ME and various component coolers for a given heat load, and to calculate the pumping power consumption to drive the cooling cycle. The pressure drop of each component and the piping are also calculated. Table 1 shows the principal methods implemented in the code.

In summary the following assumptions are considered:

- steady state simulation;

- adiabatic piping;

- isentropic pumping and compression;

- isenthalpic expansion (adiabatic);

- uniform heat load on the microprocessors (no hotspots);

- uniform flow distribution on the MEs;

- one-dimensional heat transfer in the ME

The input data required to run the simulation code are: (i) the geometrical parameters of ME's and heat exchangers, (ii) the heat load on the ME's and MP $\mathrm{AE}_{\mathrm{AE}}$, (iii) the evaporating temperature and subcooling at the ME inlet, the condensing temperature at the condenser inlet (only for the vapor compression cooling cycle), the water temperature at the condenser and subcooler inlet and outlet (secondary fluid flowing in the annulus), and (iv) the length and direction of the pipes and elbows joining the components.

The analysis took into account the thermal performance, the pumping power consumption and the total pressure drop of the cooling cycle. A comparison of 5 simulated cases considering different working fluids and cooling cycles was made. For simulated cases 1 and 4, two-phase (TP) HFC134a and single-phase liquid water (SP_W) in the ME, the design considered for the liquid pump cooling system was such that the total pressure drop was about 1.5 bar. The design constraint imposed on the condenser and the subcooler was that the pressure drops in the working and secondary fluids were, respectively, 0.05 bar and 1 bar. Cases 2, 3 and 5 considered the same heat exchanger geometries (ME, condenser and subcooler) as defined for case 1 . The difference in cases 2, 3 and 5 with respect to case 1 are that for case 2 the internal diameter of piping on the blade was reduced from $3 \mathrm{~mm}$ to $2 \mathrm{~mm}$, for case 3 the working fluid was changed from HFC134a to HFO1234ze and for case 5 the vapor compression cooling cycle was considered.

A blade server with 16 blades was taken into consideration for the total heat load. Each blade, for example as that showed in Fig. 5, presents two electronic systems in parallel and with each system being composed of one microprocessor ( $60 \mathrm{~W}$ of heat load) and the 
Table 1

Methods in the code.

\begin{tabular}{|c|c|c|}
\hline Component & Type & Method \\
\hline ME & Multi-Microchannel & $\begin{array}{l}\text { Heat transfer coefficient } \\
\text { by [54]. } \\
\text { Pressure drop as } \\
\text { suggested by [45]. } \\
\text { Critical heat flux by [44] }\end{array}$ \\
\hline \multirow[t]{3}{*}{$\begin{array}{l}\text { Condenser } \\
\text { (tube-in-tube) }\end{array}$} & $\begin{array}{l}\text { inner tube: Spiral } \mu \text {-fin } \\
\text { (single-phase flow) }\end{array}$ & $\begin{array}{l}\text { Heat transfer coefficient } \\
\text { by [32]. } \\
\text { Pressure drop by [32]. }\end{array}$ \\
\hline & $\begin{array}{l}\text { inner tube: Spiral } \mu \text {-fin } \\
\text { (two-phase flow) }\end{array}$ & $\begin{array}{l}\text { Heat transfer coefficient } \\
\text { by [9]. } \\
\text { Pressure drop by [9]. }\end{array}$ \\
\hline & $\begin{array}{l}\text { annulus: Smooth } \\
\text { (single-phase flow) }\end{array}$ & $\begin{array}{l}\text { Heat transfer coefficient } \\
\text { by [13]. } \\
\text { Pressure drop by [7]. }\end{array}$ \\
\hline \multirow[t]{2}{*}{$\begin{array}{l}\text { Subcooler } \\
\quad \text { (tube-in-tube) }\end{array}$} & $\begin{array}{l}\text { inner tube: Ribbed } \\
\text { (single-phase flow) }\end{array}$ & $\begin{array}{l}\text { Heat transfer coefficient } \\
\text { by [43]. } \\
\text { Pressure drop by [43]. }\end{array}$ \\
\hline & $\begin{array}{l}\text { annulus: Smooth } \\
\text { (single-phase flow) }\end{array}$ & $\begin{array}{l}\text { Heat transfer coefficient } \\
\text { by [13]. } \\
\text { Pressure drop by [7]. }\end{array}$ \\
\hline \multirow{3}{*}{$\begin{array}{l}\text { Straight horizontal } \\
\text { pipes } \\
\text { Straight vertical } \\
\text { pipes (upward) }\end{array}$} & $\begin{array}{l}\text { adiabatic (single-phase flow) } \\
\text { adiabatic (two-phase flow) }\end{array}$ & $\begin{array}{l}\text { Pressure drop by [7]. } \\
\text { Pressure drop by [36]. }\end{array}$ \\
\hline & adiabatic (single-phase flow) & $\begin{array}{l}\text { Pressure drop by [7] } \\
\text { and [3]. }\end{array}$ \\
\hline & adiabatic (two-phase flow) & $\begin{array}{l}\text { Pressure drop by }[6,51] \text {; } \\
{[5] \text { and [26] }}\end{array}$ \\
\hline \multirow{2}{*}{$\begin{array}{l}\text { Straight vertical } \\
\text { pipes } \\
\text { (downward) }\end{array}$} & adiabatic (single-phase flow) & $\begin{array}{l}\text { Pressure drop by [7] } \\
\text { and [3]. }\end{array}$ \\
\hline & adiabatic (two-phase flow) & $\begin{array}{l}\text { Pressure drop by }[5,6] \\
\text { and [42]. }\end{array}$ \\
\hline Elbow (horizontal) & $\begin{array}{l}\text { adiabatic (single-phase flow) } \\
\text { adiabatic (two-phase flow) }\end{array}$ & $\begin{array}{l}\text { Pressure drop by [50]. } \\
\text { Pressure drop by [4]. }\end{array}$ \\
\hline \multirow[t]{2}{*}{ Elbow (vertical) } & adiabatic (single-phase flow) & $\begin{array}{l}\text { Pressure drop by [50] } \\
\text { and [3]. }\end{array}$ \\
\hline & adiabatic (two-phase flow) & Pressure drop by [3]. \\
\hline
\end{tabular}

auxiliary electronics (55.6 W of heat load). Fig. 6 shows the rack cabinet designed, with the piping configurations and components for the liquid pump cooling cycles with water and volatile working fluid (a,b) and (c) the vapor compression cooling cycle.

In summary the following comparisons were made: i) SP_W versus TP_HFC134a, ii) TP_HFO1234ze versus TP_HFC134a, both comparisons for the liquid pump cooling cycle and iii) liquid pump cooling cycle versus vapor compression cooling cycle, both cycles with TP_HFC134a.

Table 2 shows the input data considered for each working fluid evaluated. The other thermodynamic parameters required to
Table 2

Input data.

\begin{tabular}{|c|c|c|}
\hline Component & Working fluid & Input data \\
\hline $\begin{array}{l}\text { Auxiliary } \\
\text { Electronics }\end{array}$ & All of them & $55.6 \mathrm{~W}$ per half blade \\
\hline \multirow[t]{2}{*}{$\mathrm{ME}$} & $\begin{array}{l}\text { HFC134a and } \\
\text { HFO1234ze }\end{array}$ & $\begin{array}{l}\text { Inlet evaporating temperature }=60{ }^{\circ} \mathrm{C} \\
\text { Inlet Subcooling }=0{ }^{\circ} \mathrm{C} \\
\text { Outlet vapor quality }=30 \% \\
Q_{\mathrm{ME}}=60 \mathrm{~W} \text { per ME }\end{array}$ \\
\hline & Water & $\begin{array}{l}\text { Inlet temperature }=60{ }^{\circ} \mathrm{C} \\
\text { Outlet temperature }=62{ }^{\circ} \mathrm{C} \\
Q_{\mathrm{ME}}=60 \mathrm{~W} \text { per } \mathrm{ME}\end{array}$ \\
\hline \multirow[t]{2}{*}{$\begin{array}{l}\text { Condenser } \\
\text { (tube-in-tube) }\end{array}$} & $\begin{array}{l}\text { HFC134a and } \\
\text { HFO1234ze }\end{array}$ & $\begin{array}{l}\text { Inlet condensing temperature }=95^{\circ} \mathrm{C} \\
\text { (case } 5 \text { ) } \\
\text { Outlet vapor quality }=0 \%\end{array}$ \\
\hline & $\begin{array}{l}\text { Secondary fluid: } \\
\text { water }\end{array}$ & $\begin{array}{l}\text { Inlet temperature }=15^{\circ} \mathrm{C} \\
\text { Outlet temperature }=\text { inlet condensing } \\
\text { temperature }-10^{\circ} \mathrm{C} \\
\text { Outlet temperature }=\text { inlet condensing } \\
\text { temperature }-5^{\circ} \mathrm{C} \text { (case } 5 \text { ) }\end{array}$ \\
\hline \multirow[t]{2}{*}{$\begin{array}{l}\text { Subcooler } \\
\text { (tube-in-tube) }\end{array}$} & $\begin{array}{l}\text { HFC134a and } \\
\text { HFO1234ze }\end{array}$ & Inlet vapor quality $=0 \%$ \\
\hline & $\begin{array}{l}\text { Secondary fluid: } \\
\text { Water }\end{array}$ & $\begin{array}{l}\text { Inlet temperature }=15^{\circ} \mathrm{C} \\
\text { Outlet temperature }=\text { subcooler inlet } \\
\text { temperature }-10{ }^{\circ} \mathrm{C}\end{array}$ \\
\hline Compressor & HFC134a & $\begin{array}{l}\text { Isentropic compression } \\
\text { Condensing temperature }=95^{\circ} \mathrm{C}\end{array}$ \\
\hline Liquid Pump & All of them & Isentropic pumping \\
\hline
\end{tabular}

determine the total energy balance of the cycle come from the linkage to the methods shown earlier in Table 1.

Eq. (1) shows the total energy balance of the cooling cycle:

$\underbrace{Q_{\mathrm{ME}}+Q_{\mathrm{AE}}}_{\text {Heat load }}+W_{\mathrm{LP}_{-} \text {or_VC }}=Q_{\text {cond }}+Q_{\text {sub }}$

$Q_{\mathrm{ME}}$ and $Q_{\mathrm{AE}}$ are the heat loads associated with the microprocessor and the auxiliary electronics, which are transferred respectively by the ME and MP $\mathrm{ME}_{\mathrm{AE}}$. $W_{\mathrm{LP} \_ \text {or_vc }}$ is the pumping power consumption of the driver, which can be the liquid pump or the vapor compressor. Finally, $Q_{\text {cond }}$ and $Q_{\text {sub }}$ are the heat transfer rate at the condenser and subcooler.

It is worth pointing out that the condenser is a tube-in-tube heat exchanger with spiral microfins on the internal surface of the inner tube with a smooth external surface. For the tube-in-tube subcooler, the internal surface of the inner tube is again microfinned and smooth on the external surface. For both heat exchangers the objective was to find its length, while the other geometrical

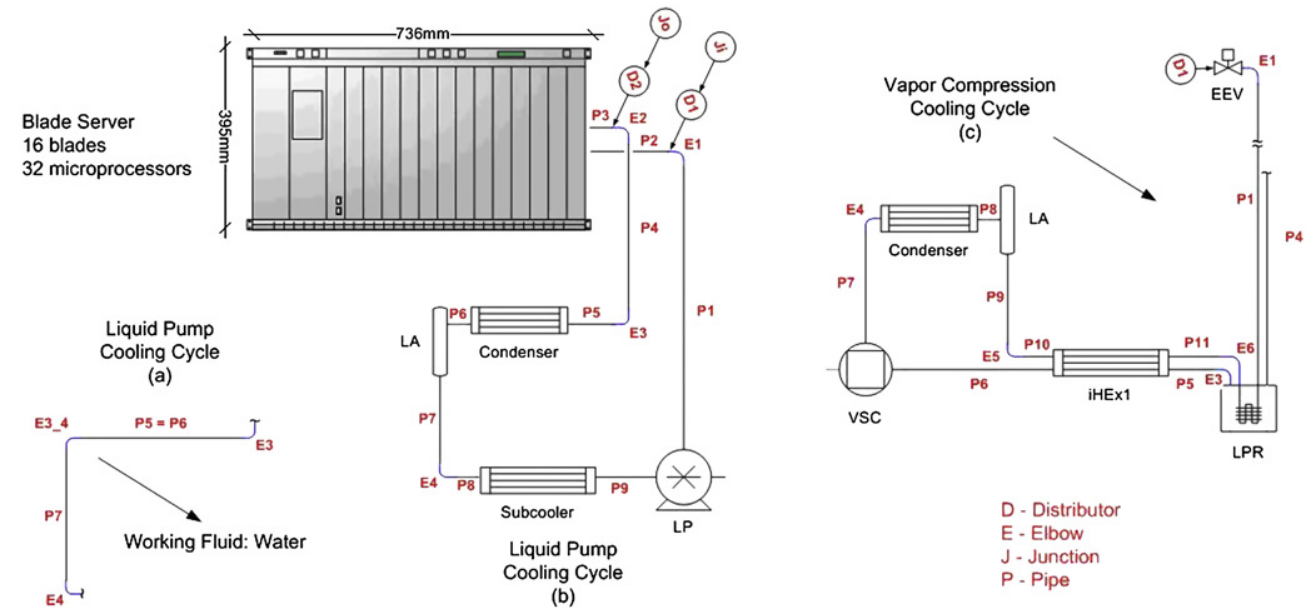

Fig. 6. Rack cabinet - Frontal view. 
parameters were considered to be fixed. Water was considered as the secondary fluid in the annulus.

Tables 3 and 4 show the geometrical parameters considered for the condenser, subcooler and ME. For the ME the same geometrical parameters were considered in all cases with the only exception being for case 4 (SP_W cooling cycle) where the orifice distribution plate, normally used at the inlet of ME's to avoid problems of maldistribution in the channels in two-phase flow [1], was not considered.

It is important to mention that for case 4 a value of $2 \mathrm{~K}$ was simulated as the maximum axial rise in the chip's temperature from inlet to outlet of the ME, which also represents the rise in the water temperature from inlet to outlet. The actual temperature rise could be more, depending on the computer manufacturer's design specifications. Increasing this temperature difference will decrease the water flow rate for its simulation, and hence also reduce its pressure drop and pumping power accordingly, but will increase the local temperature of the microprocessor at the exit. On the other hand, unless the water is charged into the server's cooling system on site, then glycol must be added to the water circuit before shipment to prevent freezing, which will increase the pressure drop by about $50 \%$. For the other TP cooling cycle cases, the maximum axial rise in the chip's temperature obtained by the ME simulations was about $0.2 \mathrm{~K}$, which is due to the near ideal matching of the tandem fall in the local flow boiling heat transfer coefficient and saturation temperature (pressure) along the micro-evaporator.

Table 5 shows the results obtained by the methods developed to evaluate the performance of the ME's. The three-zone model [54] was used for predicting the two-phase heat transfer since it was shown to predict many fluids and geometries with good accuracy [14], the numerically based model of [44] was used for critical heat flux (CHF) calculations and the homogeneous model, in conjunction with the two-phase mixture viscosity model of [10]; was used for two-phase pressure drops since it was found to predict microchannel pressure drops with relatively good accuracy [45].

The results show that a much higher mass flow rate of water is required for the SP_W cooling cycle than for the TP cooling cycles, which is justified by the latent heat of the refrigerants being 30-60 times the liquid specific heat of the water and because of the low maximum junction temperature rise defined as an input parameter. The pressure drop is low for all the fluids, in part as a consequence of the split flow design. For the outlet vapor quality considered (30\%), the predicted CHF was higher than 6 times the actual maximum heat flux of $24 \mathrm{~W} / \mathrm{cm}^{2}$. This safety factor is more than sufficient since the accuracy in predicting CHF is about $\pm 20 \%$.

Tables 6 and 7 and Figs. 7 to 9 show the simulation results for the 5 cases mentioned beforehand. The pressure drop in each component and piping, pumping power consumption, total

Table 3

Geometrical parameters/condenser and subcooler.

\begin{tabular}{|c|c|c|c|c|}
\hline \multirow{2}{*}{$\frac{\text { Cooling cycle }}{\text { Working fluid }}$} & \multicolumn{3}{|l|}{ Liquid pump } & \multirow{2}{*}{$\begin{array}{l}\text { Vapor compression } \\
\text { HFC134a }\end{array}$} \\
\hline & HFC134a or & HFO1234ze & Water & \\
\hline Heat exchanger & Condenser & Subcooler & Subcooler & Condenser \\
\hline Inner tube & Spiral $\mu$-fin & Ribbed & Ribbed & Spiral $\mu$-fin \\
\hline $\begin{array}{l}\text { Fin tip diameter } \\
\text { [mm] }\end{array}$ & 10.8 & 5.53 & 14.00 & 10.8 \\
\hline Fin height [mm] & 0.25 & 0.14 & 0.305 & 0.25 \\
\hline $\begin{array}{l}\text { Thickness of the } \\
\text { tube [mm] }\end{array}$ & 0.35 & 0.27 & 0.635 & 0.35 \\
\hline Helix angle $\left[{ }^{\circ}\right]$ & 18 & 16 & 27 & 18 \\
\hline Apex angle $\left[{ }^{\circ}\right]$ & 50 & - & - & 50 \\
\hline Number of fins [-] & 70 & 55 & 60 & 70 \\
\hline Outer tube & Smooth & Smooth & Smooth & Smooth \\
\hline $\begin{array}{l}\text { Internal diameter } \\
\quad[\mathrm{mm}]\end{array}$ & 17.52 & 8.72 & 21.33 & 17.52 \\
\hline
\end{tabular}

Table 4

Geometrical parameters of the ME.

\begin{tabular}{lrlc}
\hline Micro-evaporator & & \\
\hline Fin height $[\mu \mathrm{m}]$ & 1700 & Length $[\mathrm{mm}]$ & 13.5 \\
Fin width $[\mu \mathrm{m}]$ & 170 & Width $[\mathrm{mm}]$ & 18.5 \\
Channel width $[\mu \mathrm{m}]$ & 170 & Area $\left[\mathrm{cm}^{2}\right]$ & 2.5 \\
Base thickness $[\mathrm{mm}]$ & 1 & Material & Copper \\
Split flow & & 1 inlet and 2 outlets \\
\hline
\end{tabular}

pressure drop, heat transfer rate in the heat exchangers and their calculated length, internal diameter of piping, water mass flow rate, outlet temperature at the heat exchangers and pressure drop (secondary fluid) are shown. It is important to remember that the SP_W cooling cycle does not consider the condenser and liquid accumulator, which are not required in that cycle (see Fig. 6).

Comparing cases 1 and 4, TP_HFC134a and SP_W liquid pump cooling cycles, it is worth noting the difference regarding the internal diameter of piping and pumping power consumption. Case 4 presents the largest values, $7.7 \mathrm{~mm}$ and $35 \mathrm{~W}$, respectively. A larger pipe diameter was necessary to guarantee the 1.5 bar pressure drop defined as a design constraint, with the large pumping power being a consequence of the high mass flow rate of water (see Table 5 and Fig. 7). The pressure drop in the piping on the blade was 6 times lower for case 1 . The total length of the heat exchangers, shown in Table 7, was highest for case 1 . However, since case 4 imposed greater inner and outer tube diameters due to the $0.05 \mathrm{bar}$ and 1 bar pressure drop design constraints in the working and secondary fluid sides respectively, the volume occupied by the heat exchangers is highest for case 4 (24\% higher than for case 1 ), which represents a higher material cost. Finally, it can also be observed for all cases that the pressure drop in the piping represents more than $90 \%$ of the total pressure drop (viz. Fig. 8).

Case 2 considers a smaller internal diameter of the piping on the blade, i.e., $2 \mathrm{~mm}$, which can be advantageous for installing the cooling system on the blade due to the limited space available. The smaller diameter piping is also inherently more flexible making it easier to conform to the layout of the electronic components on the motherboard, which leads to less stress exerted on the blade. The comparison of the results between cases 1 and 2 shows an increase in pumping power and total pressure drop of about $9.4 \%$ and $7.1 \%$, respectively, although these values are still much lower than that obtained for the SP_W (case 4) presented earlier. Case 3, which considers the new environmentally friendly working fluid HFO1234ze, with the heat exchangers also having the same geometries as in case 1 , showed a small increase in pumping power consumption and total pressure drop when compared with case 1 , being on the order of $23.4 \%$ and $16.2 \%$, respectively.

Case 5 shows the simulation results of the TP_HFC134a vapor compression cooling cycle, which considers the same piping diameters and heat exchanger geometries defined for case 1 . A significant increase in pumping power is observed compared to case 1 . However, what is of interest is the lower secondary fluid

Table 5

ME performance.

\begin{tabular}{llll}
\hline Cooling cycle & TP & & SP_W \\
\hline Working Fluid & HFC134a & HFO1234ze & Water \\
\hline Inlet evaporating temperature $[\mathrm{C}]$ & 60 & 60 & - \\
Outlet evaporating temperature $[\mathrm{C}]$ & 60 & 60 & - \\
Mass flow rate per ME $[\mathrm{kg} / \mathrm{h}]$ & $\mathbf{5 . 1 8}$ & $\mathbf{5 . 3 2}$ & $\mathbf{2 5 . 8 1}$ \\
Outlet vapor quality $[\%]$ & 30 & 30 & - \\
Inlet temperature $[\mathrm{C}]$ & 60 & 60 & 60 \\
Outlet temperature $[\mathrm{C}]$ & - & - & 62 \\
Pressure drop $[$ bar] & 0.001 & 0.001 & 0.005 \\
Heat flux $\left[\mathrm{W} / \mathrm{cm}^{2}\right]$ & 24 & 24 & 24 \\
CHF $\left[\mathrm{W} / \mathrm{cm}^{2}\right]$ & 154.4 & 165.6 & - \\
\hline
\end{tabular}


Table 6

Cooling cycle piping designs and pressure drops on the blade and overall system.

\begin{tabular}{|c|c|c|c|c|c|}
\hline CASES & 1 & 2 & 3 & 4 & 5 \\
\hline Cooling Cycle & \multicolumn{4}{|c|}{ Liquid pump } & Vapor compression \\
\hline Working Fluid & HFC134a & HFC134a & HFO1234ze & Water & HFC134a \\
\hline Internal diameter of piping on the blade [mm] & 3.0 & 2.0 & 3.0 & 3.0 & 3.0 \\
\hline Internal diameter of piping for single-phase flow [mm] & 4.1 & 4.1 & 4.1 & 7.7 & 4.1 \\
\hline Internal diameter of piping for two-phase flow [mm] & 7.0 & 7.0 & 7.0 & - & 7.0 \\
\hline Pressure drop in the piping on the blade [bar] & 0.021 & 0.134 & 0.028 & 0.127 & 0.021 \\
\hline Total pressure drop [bar] & 1.54 & 1.65 & 1.79 & 1.50 & 1.87 \\
\hline
\end{tabular}

mass flow rate and heat exchanger volume and the higher outlet temperature of secondary fluid (viz. Table 7 and Fig. 9), when compared with all the cases evaluated. This implies that a lower pumping power for the secondary fluid is required while material costs of the condenser are lower due to the lower volume and that there exists a higher potential for energy recovery (high exergy). As mentioned beforehand, this cycle would be a good operating option when the energy dissipated in the condenser is recovered for other uses, for example into the feedwater heaters of thermal power plants. It is also worth mentioning that the higher heat transfer duty in the condenser (viz. Table 7 ) is associated with the additional work imparted by the compressor on the fluid. This subject will be explored in the following section.

Finally, Fig. 10 shows the effect the driver's isentropic efficiency has on the driver's power consumption for cases 1 and 5. The simulations assumed that the extra power associated with the inefficiency of the drivers was lost to the environment, i.e., it does not have an effect on the cooling cycle's thermodynamic conditions and design declared beforehand. Due to the low viscosity of HFC134a, $0.12 \mathrm{~mm}^{2} / \mathrm{s}$ at $60{ }^{\circ} \mathrm{C}$, the current pumps are not expected to have high isentropic efficiency (slip and leakage reasons/lower than $20 \%$, on the other hand conventional vapor compressors are expected to have $50 \%-70 \%$ isentropic efficiency [19] and [17]. It is also worth mentioning that such efficiency is highly dependent on the manufacturer of the driver, economic aspects and thermodynamic conditions, reasons which will not be explored in this paper.

The results show that the driver's isentropic efficiency has a considerable impact on its power consumption. For expected

Table 7

Heat exchangers simulations.

\begin{tabular}{|c|c|c|c|c|c|}
\hline CASES & 1 & 2 & 3 & 4 & 5 \\
\hline \multicolumn{6}{|l|}{ Condenser } \\
\hline Length [m] & 2.66 & 2.66 & 2.78 & - & 2.62 \\
\hline $\begin{array}{l}\text { Mass flow rate of } \\
\text { secondary fluid }[\mathrm{kg} / \mathrm{h}]\end{array}$ & 81.88 & 82.88 & 87.70 & - & 50.72 \\
\hline $\begin{array}{l}\text { Pressure drop secondary } \\
\text { fluid side [bar] }\end{array}$ & 0.954 & 0.976 & 1.129 & - & 0.374 \\
\hline $\begin{array}{l}\text { Pressure drop working } \\
\text { fluid side [bar] }\end{array}$ & 0.044 & 0.045 & 0.060 & - & 0.021 \\
\hline $\begin{array}{l}\text { Outlet temperature of } \\
\text { secondary fluid }[\mathrm{C}]\end{array}$ & 48.0 & 47.7 & 46.8 & - & 90.0 \\
\hline Heat transfer rate [W] & 3176.65 & 3199.23 & 3274.01 & - & 4445.70 \\
\hline \multicolumn{6}{|l|}{ Subcooler } \\
\hline Length $[\mathrm{m}]$ & 1.07 & 1.05 & 1.00 & 2.45 & - \\
\hline $\begin{array}{l}\text { Mass flow rate of } \\
\text { secondary fluid }[\mathrm{kg} / \mathrm{h}]\end{array}$ & 13.60 & 13.14 & 11.51 & 84.34 & - \\
\hline $\begin{array}{l}\text { Pressure drop secondary } \\
\text { fluid side [bar] }\end{array}$ & 0.981 & 0.906 & 0.687 & 1.045 & - \\
\hline $\begin{array}{l}\text { Pressure drop working } \\
\text { fluid side [bar] }\end{array}$ & 0.054 & 0.053 & 0.055 & 0.053 & - \\
\hline $\begin{array}{l}\text { Outlet temperature of } \\
\text { secondary fluid }[\mathrm{C}]\end{array}$ & 47.9 & 47.6 & 46.5 & 53.2 & - \\
\hline Heat transfer rate [W] & 528.95 & 506.97 & 433.09 & 3734.20 & - \\
\hline $\begin{array}{l}\text { Total heat exchanger } \\
\text { volume }\left[\mathrm{cm}^{3}\right]\end{array}$ & 705.2 & 704.0 & 729.9 & 875.5 & 631.6 \\
\hline
\end{tabular}

and typical efficiency values (20\% for the pump and $60 \%$ for the compressor) a power consumption of about $32 \mathrm{~W}$ and $1250 \mathrm{~W}$ are obtained for the pump and compressor, respectively. Therefore, for the expected efficiency values, the power consumption of the compressor is 39 times higher than the liquid pump, compared to 116 times higher if $100 \%$ efficiency were assumed (Fig. 7).

\section{Datacenter and coal fired power plant synergy: case study}

The case study is performed where it is considered that the datacenter uses on-chip cooling to cool the servers, with the heat captured being redistributed to a power plant. The datacenter will be modeled as a cooling cycle consisting of an evaporator (on-chip cooling elements), a condenser, a fluid driver (compressor or liquid pump), and an expansion valve in the case of a vapor compression system. The power utility will be a thermal Rankine cycle consisting of a boiler, a high and low pressure turbine, a condenser, a low pressure and high pressure feedwater pump and a feedwater heater. The feedwater heater receives heat from steam tapped after the high pressure turbine. The optimal pressure for tapping the steam will be calculated to obtain maximum thermal efficiency. The datacenter waste heat will be injected into the Rankine cycle after the condenser and prior to the feedwater heater. This is shown schematically in Fig. 11.

The operating conditions for both cycles are listed in Table 8, where the values of a typical coal fired steam cycle power plant reported by [56] are considered. A first-law analysis is performed on the two cycles, showing their overall performances. The following assumptions are made:

- no pressure drop in components;

- isentropic compression;

- isentropic pumping;

- isenthalpic expansion;

- $100 \%$ exchanger efficiency.

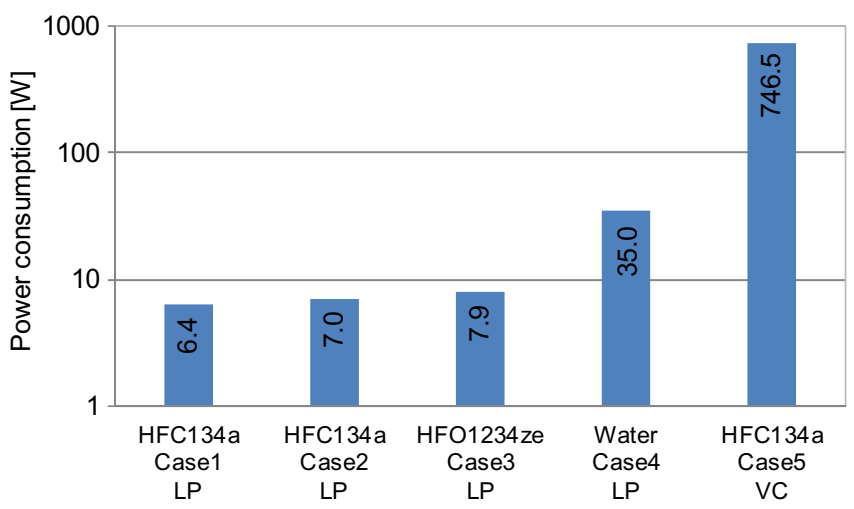

Fig. 7. Power consumption of the drivers (LP - Liquid pump, VC - Vapor compressor). 
HFC134a / Case1 / LP

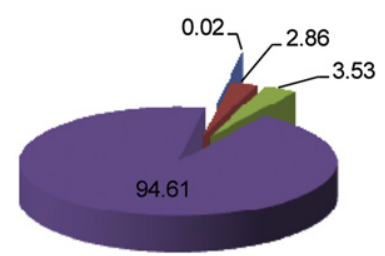

HFO1234ze / Case3 / LP

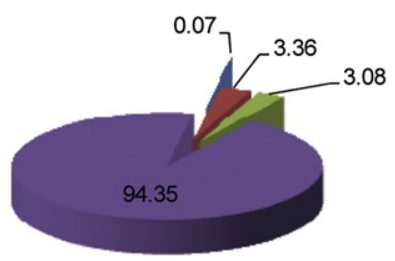

HFC134a / Case5 / VC

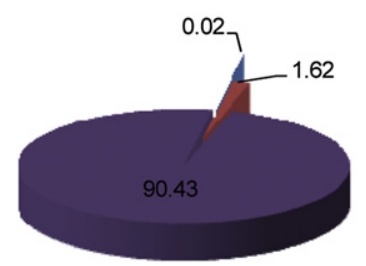

Fig. 8. Percentage breakdown of pressure drop by component.

\subsection{Power utility}

Heat captured in the datacenter can be reused by a power plant. Since the waste heat of the datacenter is of a low quality, it can only be inserted after the condenser of the power plant. This would then increase the temperature of the water leaving the condenser $\left(46^{\circ} \mathrm{C}\right.$ typically) to a maximum temperature as defined by the condensing temperature of the datacenter cycle. Therefore, any additional heat added to the power plant's cycle will result in less fuel needing to be burnt, thus saving fuel and reducing the $\mathrm{CO}_{2}$ footprint of the power plant.

Fig. 12 shows the efficiency improvement of the power plant as a function of the datacenter cycle's condensing temperature. The figure shows that the higher the condensing temperature, the greater the efficiency improvements. The efficiency of the plant can be improved by up to $2.2 \%$ if the datacenter's waste heat is reused in

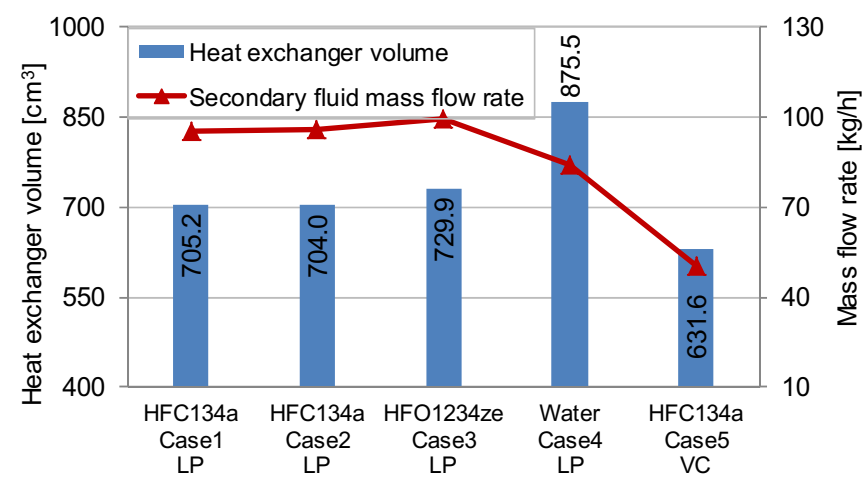

Fig. 9. Heat exchanger volume and secondary fluid mass flow rate.

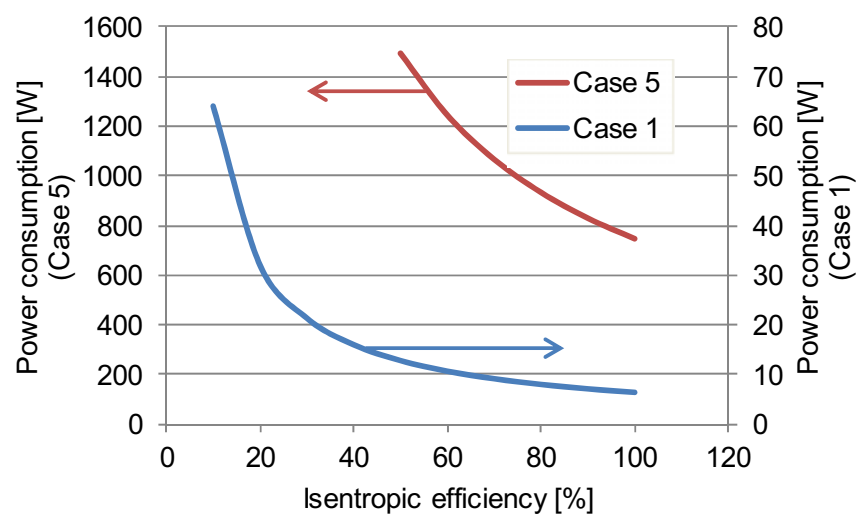

Fig. 10. Driver's power consumption vs. isentropic efficiency.

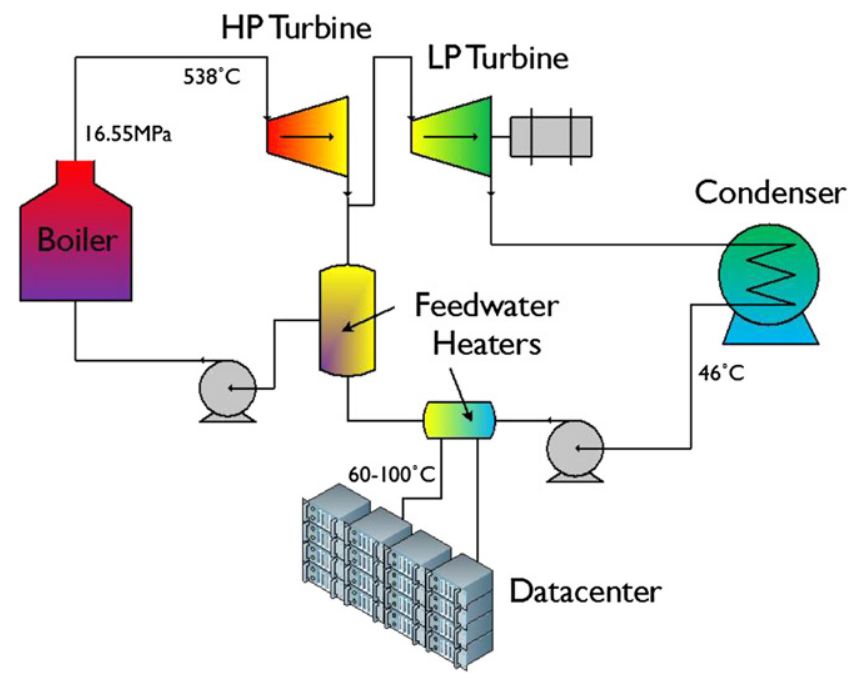

Fig. 11. Datacenter integrated in a power utility.

the power plant. By using a liquid pumping cycle in the datacenter, condensing temperatures of $60^{\circ} \mathrm{C}$ can be reached since this would imply that the evaporating temperature on the chip is also $60^{\circ} \mathrm{C}$. For higher condensing temperatures, a vapor compression cycle would be required.

In terms of $\mathrm{CO}_{2}$ footprint, Fig. 13 shows the reduction in the amount of $\mathrm{CO}_{2}$ per kilowatt-hour output per year as a function of the datacenter condensing temperature. Also shown on the graph is the amount of $\mathrm{CO}_{2}$ saved per kilowatt-hour output per year. These values assume that coal is used as the source of the power plant's energy and will be less for other types of fuel. Therefore, if a power plant with an output capacity of $500 \mathrm{MW}$ were considered, the savings in $\mathrm{CO}_{2}$ would be in the order of 195000 tons of $\mathrm{CO}_{2}$ per year. This could potentially save about $\$ 3000000$ per year if a carbon tax of $\$ 15$ per ton of $\mathrm{CO}_{2}$ [23] was considered.

Table 8

Operating conditions for the power utility and datacenter cooling cycle.

\begin{tabular}{lll}
\hline & Power utility & Datacenter cooling \\
\hline & Boiler & Evaporator \\
Pressure $[\mathrm{MPa}]$ & 16.55 & 1.681 \\
& Turbine & Compressor \\
Inlet Pressure $[\mathrm{MPa}]$ & 16.55 & 1.681 \\
Inlet Temperature $[\mathrm{C}]$ & 538 & 70 \\
& Condenser & \\
Condensing Temperature $[\mathrm{C}]$ & 46 & $60-100$ \\
\hline
\end{tabular}




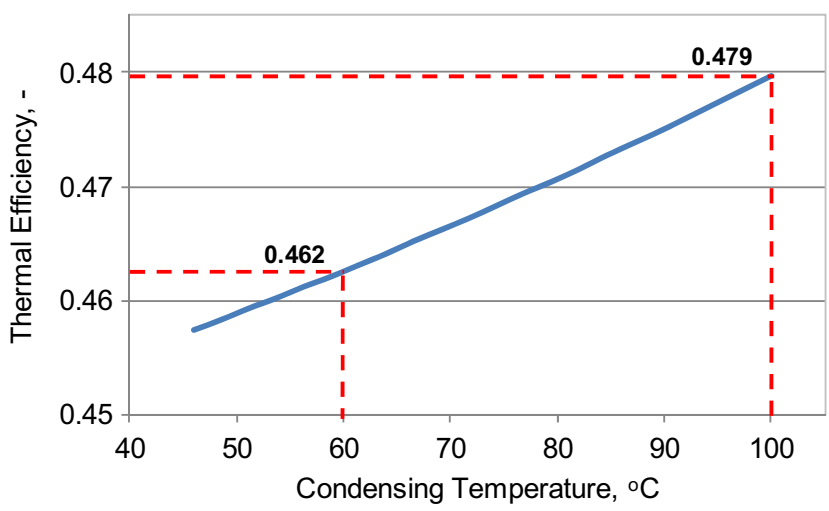

Fig. 12. Thermal efficiency of power plant.

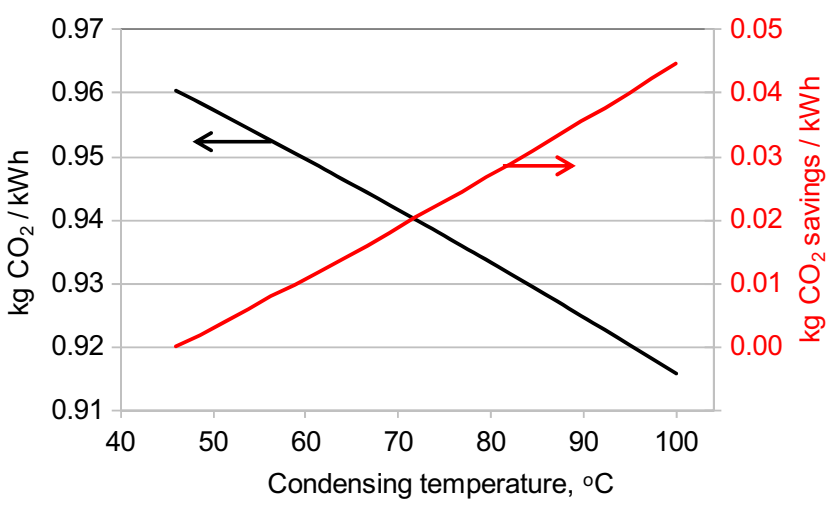

Fig. 13. $\mathrm{CO}_{2}$ footprint and savings per kilowatt-hour.

\subsection{Datacenter}

Due to datacenter growth, it is more than likely to see datacenters in excess of 100000 servers (viz. Fig. 14). Therefore, the simulations following will be based on a datacenter containing 100000 servers, with each server generating $325 \mathrm{~W}$, which includes the main processor and auxiliary electronics (memories, DC-DC converters, hard drives, etc). Fig. 15 shows a graph of the total power supply required by the datacenter to operate the IT equipment and the cooling system. Included in the graph is on-chip two-phase cooling methods using a vapor compression cycle and liquid pumping cycle. As a comparison, traditional air cooling units are also simulated, where it is assumed that their power consumption is the same as that required to operate the IT equipment ([22] and [21]). The results are plotted as a function of the compressor or pump overall efficiencies (defined as the ratio between isentropic compression or pumping power and the electrical power for the drivers). All simulations were developed for an evaporating temperature of $60{ }^{\circ} \mathrm{C}$ (on the chip), with condensing temperatures being $60{ }^{\circ} \mathrm{C}$ and $90{ }^{\circ} \mathrm{C}$ for the liquid pumping and vapor compression cycles, respectively.

It is seen that the cycle using a vapor compressor has a strong function of the compressor's overall efficiency, up to a value of approximately $35 \%$ after which it becomes less dependent. Typically, compressors have an overall efficiency of about $60 \%$. The liquid pumping cycle hardly shows any dependence on the pump efficiency. This is due to the power required to drive the pump being very low [28]. The higher power consumption of the compressor is due to the energy required to increase the pressure from a saturation temperature of $60^{\circ} \mathrm{C}$ to $90^{\circ} \mathrm{C}$. What is noticed, though, is that the datacenter's power requirements are reduced considerably for overall efficiencies above $15 \%$ (vapor compression cycle) when compared to traditional air cooling. This reduction is in

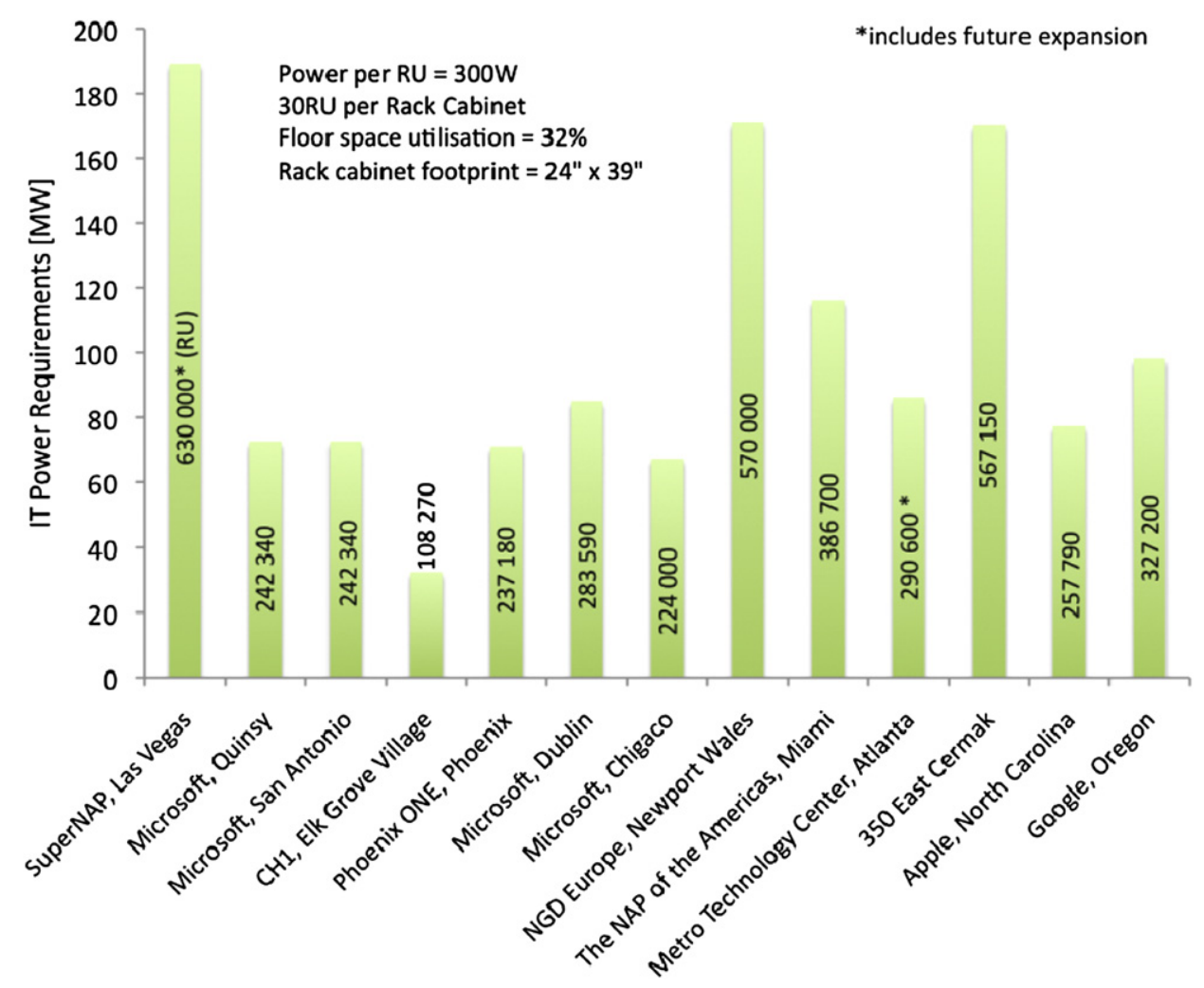

Fig. 14. Datacenter size and information technology (IT) power requirements. 


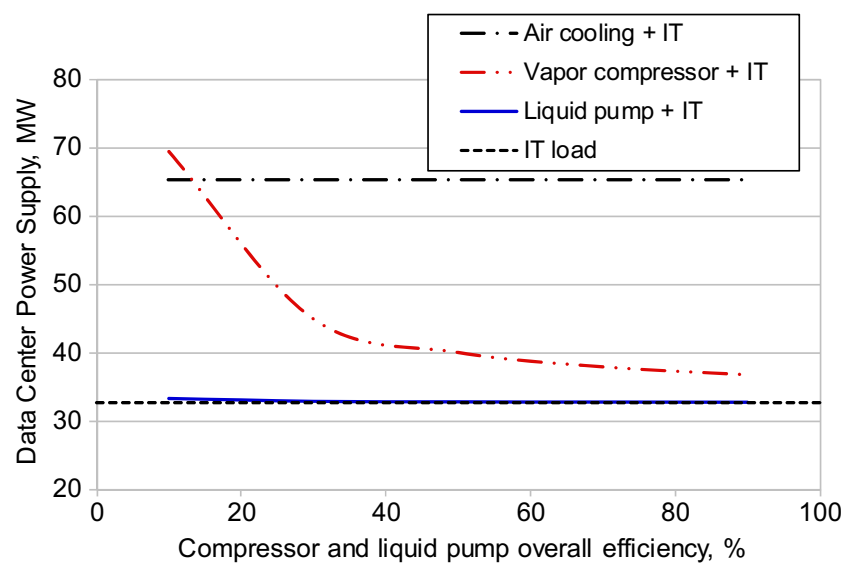

Fig. 15. Datacenter power supply - IT and cooling system.

the order of $50 \%$ when using a liquid pumping cycle and $41 \%$ for a vapor compression cycle with a compressor having an overall efficiency of $60 \%$.

Further savings can be made when energy recovery is considered. Since on-chip cooling is used, recovering this energy would be a simple process by just incorporating a condenser, where the energy absorbed by the fluid from the server is transferred to a secondary fluid, like water, in the condenser. Fig. 16 shows a graph of the datacenter power supply for the three types of cooling technologies as a function of the efficiency with which energy is recovered. $100 \%$ efficiency implies that all the heat generated by the servers is recovered, while $0 \%$ means that none of the heat is recovered. Note that there is no change in power consumption for air cooling as it was assumed that the heat was not recovered, although this technology does exist, albeit not as effective as for liquid cooling. The plots for the liquid pumping and vapor compression cycles assume that the pump and compressor has an overall efficiency of $100 \%$ and $60 \%$, respectively, although the choice of efficiency for the pump is negligible (viz. Fig. 15). It should be noted that $0 \mathrm{MW}$ datacenter supply does not mean the datacenter requires no power, but rather that all the power received as electricity is sold as heat. The financial implications would show this since the value of the heat sold would be different from the electricity purchased and will be a function on the application to which the heat is sold.

Fig. 16 shows that practically all the power purchased in the form of electricity can potentially be sold as heat. This is especially

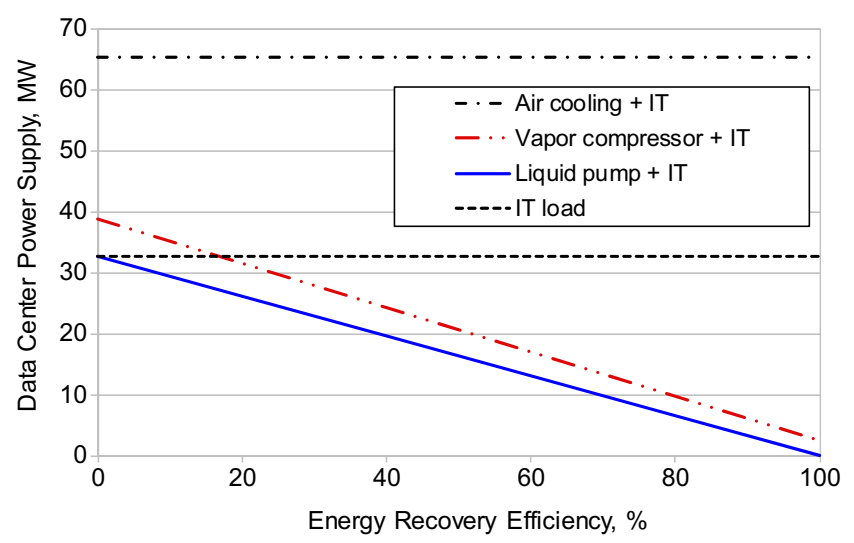

Fig. 16. Datacenter power supply - IT and cooling system - potential of energy recovery. the case for a liquid pumping cycle due to its energy consumption being very low. The vapor compression cycle always has some unrecoverable heat due to inefficiencies, with this heat being lost to the environment. At this point in stage it would appear as if the use of a liquid pumping cycle far outweighs the vapor compression cycle. However, what the graphs do not show is the quality of the heat being sold. The former can sell heat at a temperature of $60^{\circ} \mathrm{C}$, while the latter can sell it at $90^{\circ} \mathrm{C}$. The quality of heat is therefore important, not only due to the monetary value it adds, but also to the application to which it is sold. A limited number of applications can use $60{ }^{\circ} \mathrm{C}$ of heat, with the limits becoming less as the temperature is increased.

\subsection{Exergy analysis}

To better explore and understand the difference between the two possibilities of cooling cycles (vapor compressor and liquid pump) regarding energy recovery, i.e., exergy available at the condenser for a secondary application, the concept of exergy is introduced. The cooling cycles defined in the previous section were considered (viz. Figs. 3 and 4). For this analysis the heat load of an entire blade center composed of 14 blades, which has the microprocessors and auxiliary electronics to be cooled, is defined as a heat source of $4900 \mathrm{~W}$ at $85{ }^{\circ} \mathrm{C}$, while a counter-flow heat exchanger is used as the condenser. The secondary fluid is water at an inlet and outlet temperature of $46{ }^{\circ} \mathrm{C}$ and $5{ }^{\circ} \mathrm{C}$ lower than the inlet temperature of working fluid, respectively. [38] showed for energy recovery applications, that $46^{\circ} \mathrm{C}$ is about the condenser outlet temperature of a coal power plant, being the potential point where the recovered heat of a datacenter can be injected. An overall efficiency of $60 \%$ was considered for the drivers, i.e., pump and compressor. HFC134a is used as working fluid and a $\mathrm{ME}+\mathrm{MP}_{\mathrm{AE}}$ evaporating temperature of $60^{\circ} \mathrm{C}$ is defined. An outlet vapor quality of about $80 \%$ at the $\mathrm{MP}_{\mathrm{AE}}$ is obtained from the simulations of both cycles. The mass flow rate of the working fluid and secondary fluid were adjusted so that the energy balance is respected.

The steady state exergy rate balance is defined by Eq. (2) [35]. The first and second terms in the right side of equality represent the exergy transfer accompanying heat and work, the third and fourth are the time rate of exergy transfer accompanying mass flow and flow work and, finally, the last term is the rate of exergy destroyed. With some mathematical manipulation it is possible to prove that the last term in Eq. (2), i.e., $\dot{E}_{d}$ is the entropy generation multiplied by the dead state temperature $T_{0}$.

$$
\begin{aligned}
0= & \underbrace{\sum_{j}\left(1-\frac{T_{0}}{T_{j}}\right) \dot{Q}_{j}-\dot{W}_{\mathrm{cv}}+\sum_{i} \dot{m}_{i} e_{\mathrm{fi}}-\sum_{e} \dot{m}_{e} e_{\mathrm{fe}}}_{\text {rate of exergy destruction }} \\
-\underbrace{\dot{E}_{d}}_{\text {rate of exergy transfer }} &
\end{aligned}
$$

It can be observed that an exergy reference environment is necessary to be defined. Such an environment represents the state of equilibrium or dead state. This equilibrium state defines the exergy as the maximum theoretical work obtainable when another system in a non-equilibrium state interacts with the environment to the equilibrium. For the present work, the reference is defined as $295 \mathrm{~K}, 100 \mathrm{kPa}$ for water and $295 \mathrm{~K}, 603.28 \mathrm{kPa}$ and $50 \%$ of vapor quality for HFC134a.

The goal of the analysis is to determine, for each cycle, the exergy supplied, recovered and destroyed for a control volume in the cooling cycle. With this the overall exergetic efficiency, defined as the ratio between recovered and supplied exergies, can be 
determined. The exergetic efficiency of each component is also evaluated. It qualitatively identifies and classifies the components that present higher irreversibilities, helping to decide which component to optimize to improve the thermodynamic performance of the cooling cycle.

Table 9 shows the results obtained regarding exergy and energy. For this analysis it is worth mentioning that the piping connecting the main components is considered to be adiabatic having no pressure losses, while the potential and kinetic energy effects in the cooling cycles are also neglected.

First, it can be seen that the total exergy recovered is higher for the VC cooling cycle, which is a consequence of the higher exergy supplied by the driver used in this cycle. It is highlighted here that this high exergy is the subject of interest of the owner of a coal fired power plant presented beforehand, as will be discussed in the following sections.

Of the components considered in the cooling cycles, the driver showed the lowest exergetic efficiency, which implies that to improve the thermodynamic performance of the cooling cycles the first component to be optimized in the design would be the driver. It is important to mention that since the simulations considered a fixed driver overall efficiency and the heat losses and pressure drops in the piping were neglected, means that such an analysis is limited to the main components of the cycle and a complete simulation must be done to generalize the conclusions.

It can also be observed that the overall exergetic efficiency is lower for the VC cooling cycle, with the compressor and $\mathrm{ME}+\mathrm{MP}_{\mathrm{AE}}$ being the main culprits. The overall exergetic efficiency also shows that there is a huge need to improve the thermodynamic performance of the cooling cycle, since less than $50 \%$ of the available exergy is used.

Fig. 17 shows the exergetic efficiency as a function of the driver overall efficiency. It can be seen that the exergetic efficiency increases when the overall efficiency increases and the VC cooling cycle starts to be the best exergetic option after a driver overall efficiency of about 67\%. It can be concluded that for a proper utilization of exergy the VC cooling cycle must have an overall efficiency higher than $67 \%$. Only in this way such a cycle is competitive with the LP cooling cycle, which showed low effect of the driver overall efficiency on the exergetic efficiency.

Finally, it is important mentioning that the thermodynamic performance alone (energy balance) does not permit the analysis

Table 9

Exergy and energy balance results.

\begin{tabular}{|c|c|c|c|c|c|}
\hline \multicolumn{6}{|l|}{ Energy balance } \\
\hline Energy in & LP cycle & VC cycle & Energy out & LP cycle & VC cycle \\
\hline $\begin{array}{l}\text { Pump or compressor } \\
\text { input power [W] }\end{array}$ & 35.49 & 1126 & $\begin{array}{l}\text { Heat out in the } \\
\text { condenser [W] }\end{array}$ & 4921.29 & 5575.5 \\
\hline $\begin{array}{l}\text { Heat added in the } \\
\mathrm{ME}+\mathrm{MP}_{\mathrm{AE}}[\mathrm{W}]\end{array}$ & 4900 & 4900 & & & \\
\hline \multicolumn{6}{|l|}{ Exergy balance } \\
\hline & LP cycle & VC cycle & & LP cycle & VC cycle \\
\hline Exergy supplied [W] & 900.8 & 1991 & $\begin{array}{l}\text { Exergy } \\
\text { recovered [W] }\end{array}$ & 428.1 & 890 \\
\hline $\begin{array}{l}\text { Exergy destroyed or } \\
\text { irreversibility [W] }\end{array}$ & & & $\begin{array}{l}\text { Exergetic } \\
\text { efficiency [\%] }\end{array}$ & & \\
\hline Pump or compressor & 14.2 & 450.4 & $\begin{array}{l}\text { Pump or } \\
\text { compressor }\end{array}$ & 60.0 & 60.0 \\
\hline Condenser & 137.6 & 209.2 & Condenser & 75.7 & 81.0 \\
\hline $\mathrm{ME}+\mathrm{MP}_{\mathrm{AE}}$ & 320.9 & 320.8 & $\mathrm{ME}+\mathrm{MP}_{\mathrm{AE}}$ & 62.3 & 62.3 \\
\hline iHEx & - & 39.12 & iHEx & - & 82.8 \\
\hline LPR & - & 25.86 & LPR & - & 82.3 \\
\hline EEV & - & 55.79 & EEV & - & 0 \\
\hline Total & 472.7 & 1101 & Overall & 47.5 & 44.7 \\
\hline
\end{tabular}

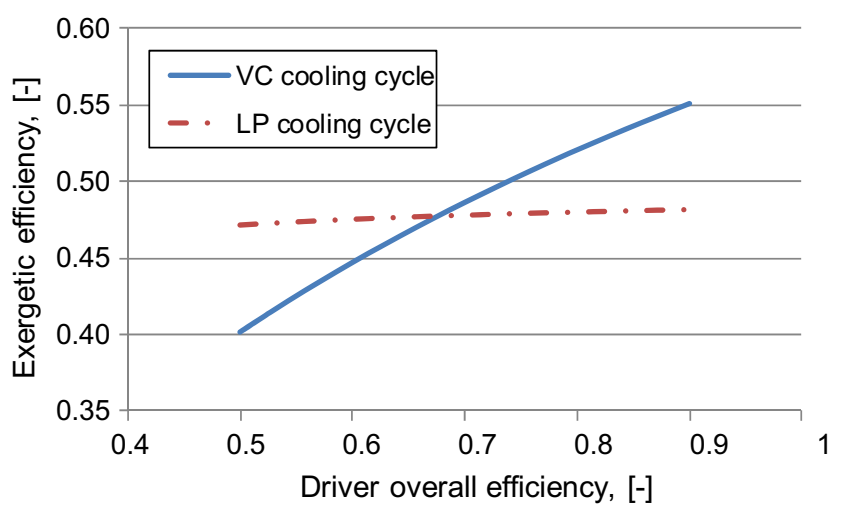

Fig. 17. Exergetic efficiency versus driver overall efficiency.

showed beforehand. Exergy analysis clearly identifies efficiency improvements and reductions in thermodynamics losses attributable to green technologies. Additional advantages of such analysis are the potential to evaluate green technology aspects such as environmental impact or sustainable development (normally associated with carbon dioxide emissions) and economics ("exergy, not energy, is the commodity of value in a system, and assign costs and/or prices to exergy-related variables") [46].

\subsection{Carbon footprint}

For the calculation of the carbon footprint, only the contribution of the electricity used is considered. The effect of greenhouse gases (GHG) being formed by the manufacturing, transporting, storage and disposal of the components of the datacenter, as well as the datacenter building, fall under the Life Cycle Assessment, which falls outside the scope of the current paper. Further, of the greenhouse gases, only $\mathrm{CO}_{2}$ will be considered as it contributes to more than $75 \%$ of all the greenhouse gases and contributes the most to the greenhouse effect. Fig. 18 shows the reduction of the quantity of $\mathrm{CO}_{2}$ for the three cooling technologies as a function of the efficiency with which the energy is recovered. The quantity of $\mathrm{CO}_{2}$ is calculated with the assumption that the datacenter purchases its electricity from a power plant running on coal and that it is selling waste heat back to the power plant, as discussed earlier. This graph, therefore, takes into consideration the efficiency increase of the power plant, since the amount of $\mathrm{CO}_{2}$ released is a function of the power plant's efficiency, which in itself is a function of the efficiency with which energy is recovered.

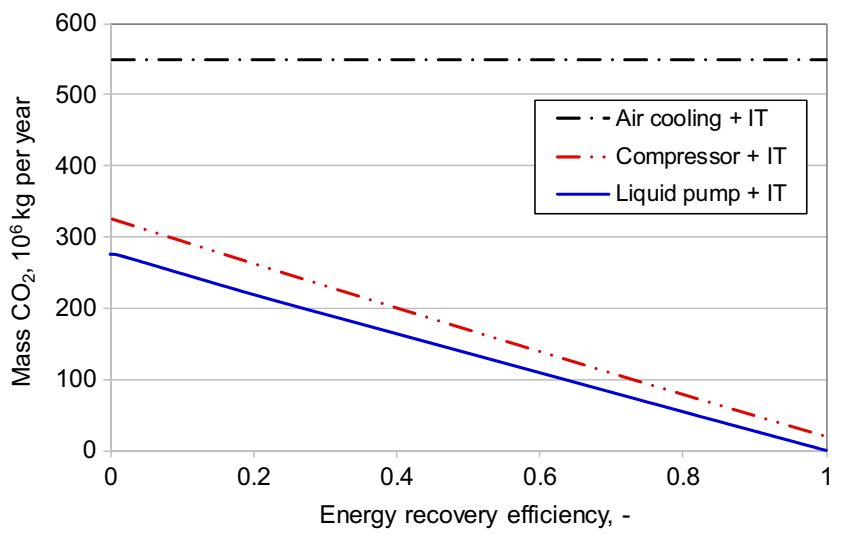

Fig. 18. Reduction in $\mathrm{CO}_{2}$ for three datacenter cooling technologies. 
The figure shows that the datacenter could potentially have a zero carbon footprint regarding electricity usage when on-chip cooling using a liquid pumping or vapor compression cycle is used. The use of a liquid pumping or vapor compression cooling cycle without energy recovery ( $0 \%$ recovery efficiency), compared to traditional air cooling, reduces the carbon footprint of the datacenter considerably, with a reduction of $50 \%$ for the former and $40 \%$ for the latter. This reduction is improved further with energy recovery, with a potential reduction of almost $100 \%$ and $96 \%$ being achievable.

As observed previously, Fig. 18 does not show the quality of the heat being recovered, with the value and applicability of this heat not being clear. This can be seen more clearly when applying the waste heat to the thermal power plant, which is shown in Fig. 19. This graph shows the $\mathrm{CO}_{2}$ reduction of the datacenter due to energy recovery and the savings in $\mathrm{CO}_{2}$ of the power plant due to efficiency improvements. Instead of plotting the carbon footprint as a function of the recovery efficiency it is plotted as a function of the condenser temperature, which is directly linked to the feedwater heater of the power plant. The effect is the same since a lower energy recovery efficiency would result in lower temperature increases of the power plant's feedwater and, hence, lower efficiency increases. The graph therefore shows the limit of each cooling cycle. Since the power plant's thermal efficiency improves with increase in condenser temperature, the amount of $\mathrm{CO}_{2}$ saved by the power plant increases. However, when using a liquid pumping cycle for the datacenter, only $25 \%$ of the total potential savings in $\mathrm{CO}_{2}$ can be achieved, amounting to approximately 17000 tons per year for a $173 \mathrm{MW}$ power plant. By making use of a vapor compression cycle, however, the potential savings in $\mathrm{CO}_{2}$ can reach as high as 70000 tons per year. Therefore, although the liquid pumping cycle was the better performing cooling cycle regarding energy usage and $\mathrm{CO}_{2}$ reduction, due to the higher temperatures achievable the vapor compression cycle has a larger impact on the secondary application making use of the waste heat.

Of course, depending on the point of view taken, it may be argued that due to the savings the power plant is making in $\mathrm{CO}_{2}$ due to the datacenter, the datacenter could claim those savings as part of its own reduction. This could potentially then lead to the datacenter having a negative carbon footprint regarding energy usage, which it can then use as a carbon offset, as shown in Fig. 20. This offset could be used to compensate for other $\mathrm{CO}_{2}$ emitting processes in the datacenter, or can even be sold to other organizations as is done in carbon-trading. This should, however, be viewed as a tentative idea as regulations would determine whether this is possible or not. However, if this were the case, by making use of a vapor compression cycle, the offset could be $167 \%$ more than when using a liquid pumping cycle.

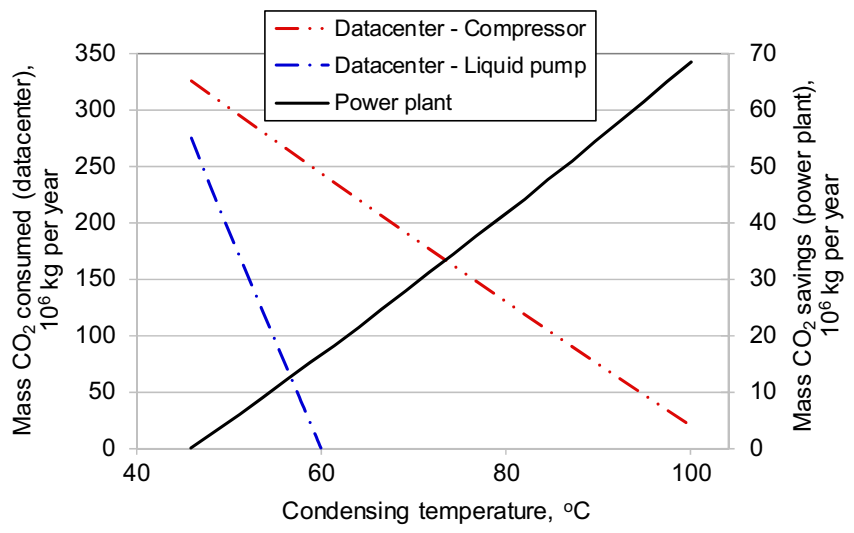

Fig. 19. Carbon footprint of datacenter and $\mathrm{CO}_{2}$ savings of power plant.

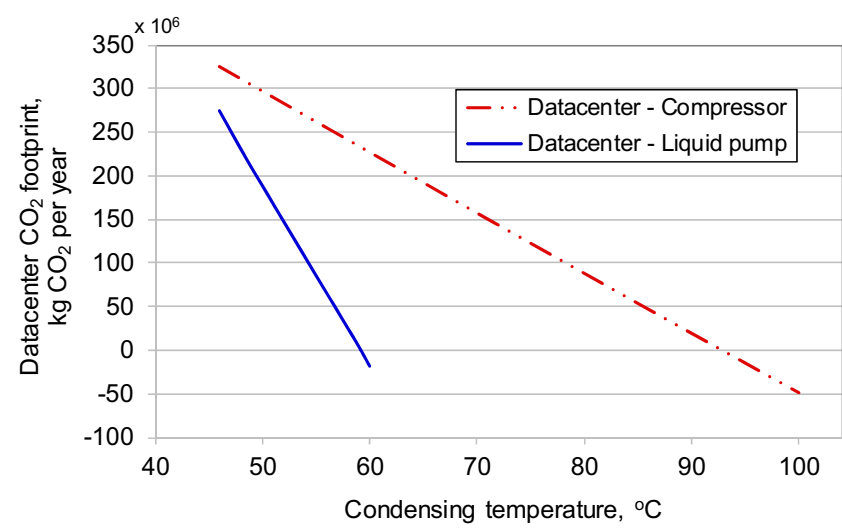

Fig. 20. $\mathrm{CO}_{2}$ footprint of a datacenter considering $\mathrm{CO}_{2}$ reduction of power plant.

\subsection{Monetary savings}

Global warming is having a huge impact on the environment and on the livelihood of people regarding food production and natural resources. To counter this, a carbon tax is being introduced, which is aimed at helping the environment by not only reducing carbon emissions by forcing people and organizations to become more energy-efficient, but also by raising funds to be used for clean energy research. The tax is levied on the carbon content of fuels, increasing the competitiveness of non-carbon technologies such as solar, wind or nuclear energy sources. Therefore, organizations using electricity produced from the burning of fossil fuels will pay a higher tax than those produced from non-carbon burning fuels. The probability also exists for taxing the utility generating the electricity. Carbon taxes have only been introduced in a few countries, with most European countries taking the lead, even though the way organizations are being taxed vary from country to country. In the United States the introduction of carbon tax has been made in California and the city of Boulder, Colorado, with taxes being in the order of 4 cents/ton of $\mathrm{CO}_{2}$. European countries have been much more stringent with taxes in some countries, such as Sweden, being as high as $\$ 100$ per ton of $\mathrm{CO}_{2}$ [8]. The Larson Bill [23] proposes to introduce a nationwide tax (US) of $\$ 15 /$ ton $\mathrm{CO}_{2}$ starting in 2012 , increasing by $\$ 10 /$ ton $\mathrm{CO}_{2}$ every year. It also proposes to increase this increment to $\$ 15 /$ ton $\mathrm{CO}_{2}$ after 5 years if the US emissions stray from the Environmental Protection Agency's (EPA) glide-path prediction, which proposes to cut emission to $80 \%$ that of 2005 levels by 2050 .

With a recommended price of $\$ 30 /$ ton $\mathrm{CO}_{2}$ [37] could cost industries millions if efficiencies are not improved. Datacenters are

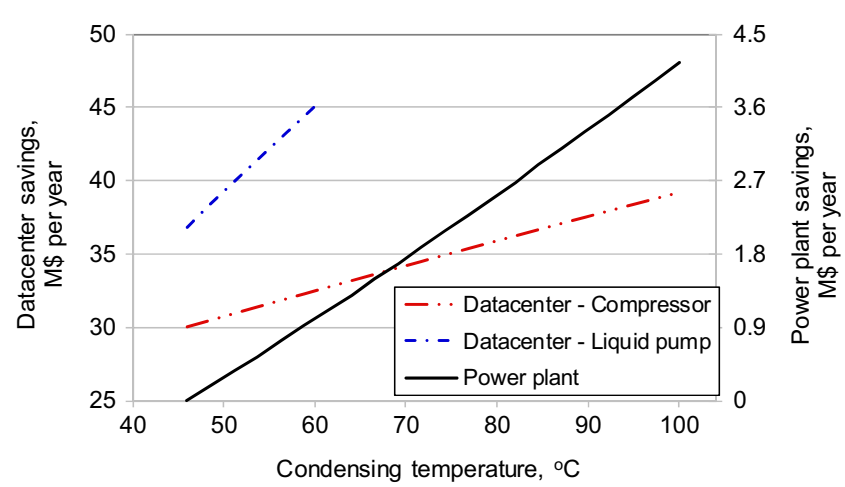

Fig. 21. Datacenter and power plant savings. 


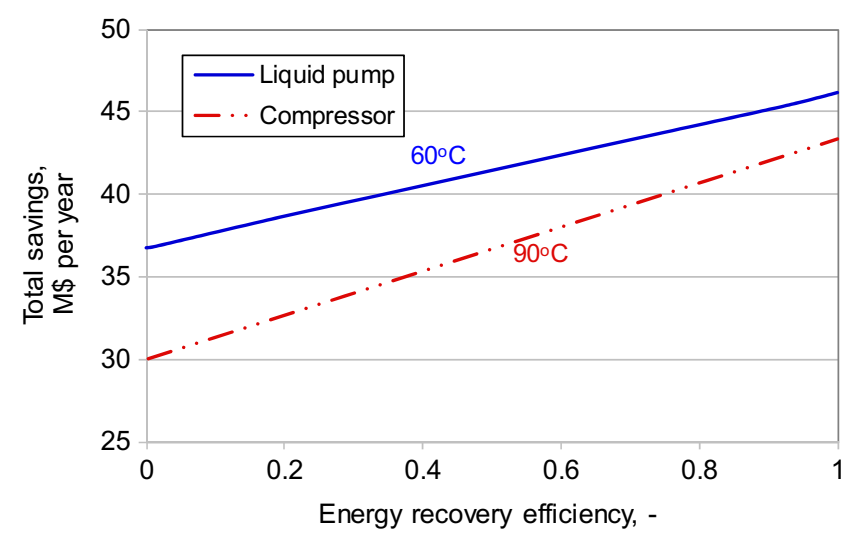

Fig. 22. Total savings for liquid pumping and vapor compression cooling technologies.

also not exempt from these taxes, which will be introduced in the following years to come [33]. Fig. 21 shows the potential savings made by a datacenter with a size of 100000 servers and a coal power plant with a size of $175 \mathrm{MW}$ if heat were captured from the datacenter and sold to the power plant. The savings not only includes that saved in energy costs by implementing a liquid pumping or vapor compression cycle instead of a traditional air cooling cycle, but also that saved in carbon tax. The savings of the power plant is in terms of fuel saved and the savings made in carbon tax. For fuel costs, a value of $\$ 90 /$ ton of coal was used.

For the datacenter, the graph shows that most savings are made if a liquid pumping cycle was used, with the potential savings being in the order of $\$ 45000000$ per year, while a vapor compression cycle would save in the order of $\$ 40000000$ per year. The power plant, when recovering heat from a datacenter using a liquid pumping cycle, will only save about $\$ 1000000$ per year, with savings reaching almost $\$ 400000$ a year if a vapor compression cycle were used.

The overall savings are given in Fig. 22. This graph shows that the total savings, if a datacenter was to sell waste heat at $60^{\circ} \mathrm{C}$ with a liquid pumping cycle, could be about $\$ 46000000$ a year, while selling heat at $90{ }^{\circ} \mathrm{C}$ with a vapor compression cycle could save a total of $\$ 43000000$ per year. These are savings that a customer would potentially not have to pay. Even though it seems as if the clear solution is to use a liquid pumping cycle within a datacenter, the incentive for a power plant to cooperate with a datacenter would be greater if a vapor compression cycle was used.

\section{Conclusion}

A hybrid two-phase cooling cycle has been proposed and simulated to cool microprocessors and auxiliary electronics of blade server boards with two-phase evaporating flow in the microevaporator cooling elements. A simulation code was developed and 5 cases were simulated considering 3 different working fluids, HFC134a, HFO1234ze and water (in an analogous single-phase cooling cycle) and different internal diameters of the pipes and elbows joining the components. The results showed that the liquid water cooling cycle has a pumping power consumption 5.5 times that obtained for the two-phase HFC134a cooling cycle, both considering a liquid pump as the driver of the fluid. When compared with the HFO1234ze cooling cycle the difference drops to 4.4 times. The simulation of the vapor compression cooling cycle showed higher pumping power consumption when compared with the other cycles simulated. However, this cycle can be justified when the waste heat at the condenser is recovered for applications such as district heating and preheating of boiler feedwater.
An exergy analyses of the cooling cycles, regarding the potential of exergy recovery at the condenser, showed a low overall exergetic efficiency (lower than 50\%), meaning that improvements can be done to increase the thermodynamic performance of the cycles. When looking at local effects, such analyses showed that the driver and the $\mathrm{ME}+\mathrm{MP}_{\mathrm{AE}}$ are the components with the lowest exergetic efficiency and would be the main components to be improved in terms of thermodynamic design. It was also shown that the overall exergetic efficiency of the vapor compression cooling cycle is strongly influenced by the compressor overall efficiency, which showed to be more exergeticaly efficient than the liquid pumping cooling cycle for an overall efficiency higher than $67 \%$.

A case study was developed to investigate the potential savings in energy a datacenter can make by implementing on-chip cooling with waste heat recovery. As an application for the waste heat, a coal fired power plant was analyzed. The results showed that, when compared with traditional air cooling systems, the energy consumption of the datacenter could be reduced by as much as $50 \%$ when using a liquid pumping cycle and $41 \%$ when using a vapor compression cycle. The overall consumption can be reduced even further if the recovered energy is sold to a secondary application, such as a thermal power plant. Power plant thermal efficiency improvements in the order of $2.2 \%$ are possible if datacenter waste heat is incorporated in the power plant's feedwater. This could imply huge savings in terms of fuel as well as carbon tax due to a reduced carbon footprint.

\section{Acknowledgements}

The Commission for Technology and Innovation (CTI) contract number 6862.2 DCS-NM entitled "Micro-Evaporation Cooling System for High Performance Micro-Processors: Development of Prototype Units and Performance Testing" directed by the LTCM laboratory sponsored this work along with the project's industrial partners: IBM Zürich Research Laboratory (Switzerland) and Embraco (Brazil). J.B. Marcinichen wishes to thank CAPES ("Coordenação de Aperfeiçoamento de Pessoal de Nível Superior") for a one year fellowship to work at the LTCM laboratory. The authors also wish to thank Honeywell Inc. for providing the thermophysical properties of HFO1234ze for the calculations.

\section{References}

[1] B. Agostini, M. Fabbri, J.E. Park, L. Wojtan, J.R. Thome, B. Michel, State of the art of high heat flux cooling technologies, Heat Transfer Engineering 28 (2007) $258-281$.

[2] B. Agostini, M. Fabbri, J.R. Thome, B. Michel, High heat flux two-phase cooling in silicon multimicrochannels, IEEE Transactions on Components and Packaging Technologies 31 (3) (2008) 691-701.

[3] A. Azzi, U.S.T.H.B. Alger, L. Friedel, Two-phase upward flow $90^{\circ}$ bend pressure loss model, Forschung im Ingenieurwesen 69 (2005) 120-130.

[4] A. Azzi, L. Friedel, S. Belaadi, Two-phase gas/liquid flow pressure loss in bends, Forschung im Ingenieurwesen 65 (2000) 309-318.

[5] A. Barnea, Transition from annular flow and from dispersed bubble flow unified models for the whole range of pipe inclinations, International Journal of Multiphase Flow 12 (5) (1986) 733-744.

[6] D. Barnea, O. Shoham, Y. Taitel, Flow pattern transition for vertical downward two phase flow, Chemical Engineering Science 37 (5) (1982) 741-744.

[7] H. Blasius, Das Ähnlichkeitsgesetz bei Reibungsvorgängen in Flussigkeiten (1913) Fors-chg. Arb. Ing. -Wes., 131 Berlin.

[8] Carbon Tax, In Wikipedia, the Free Encyclopedia Retrieved 08:12, July 26 2010, (2010) Available from: http://en.wikipedia.org/w/index.php? title=Carbon_tax\&oldid=374709823::

[9] A. Cavallini, D. Del Col, L. Doretti, G.A. Longo, L. Rossetto, Heat transfer and pressure drop during condensation of refrigerants inside horizontal enhanced tubes, International Journal of Refrigeration 23 (2000) 4-25.

[10] A. Cicchitti, C. Lombardi, M. Silvestri, G. Soldaini, R. Zavattarelli, Two-phase cooling experiments-pressure drop, heat transfer and burnout measurements, Energia Nuclear 7 (1960) 407-425.

[13] F.W. Dittus, L.M.K. Boelter, Publications on Engineering, vol. 2, University of California, Berkeley, 1930, 443 
[14] V. Dupont, J.R. Thome, A.M. Jacobi, Heat transfer model for evaporation in microchannels. Part II: comparison with the database, International Journal of Heat and Mass Transfer 47 (2004) 3387-3401.

[15] EPA, Report to Congress on Server and Data Center Energy Efficiency Public Law pp. 109-431, U.S. Environmental Protection Agency, 2007.

[16] P. Ganapati, Water-Cooled Supercomputer Doubles as Dorm Space Heater Retrieved 12:12, February 18, 2011, (2009) Available from: http://www. wired.com/gadgetlab/2009/06/ibm-supercomputer/.

[17] J.M. Gonçalves, C. Melo, C.J.L. Hermes, J.R. Barbosa, Experimental mapping of the thermodynamic losses in vapor compression refrigeration systems, Journal of the Brazilian Society of Mechanical Sciences and Engineering 33 (2)(2011) 159-165.

[18] R. Hannemann, J. Marsala, M. Pitasi, Pumped liquid multiphase cooling, in: Proceedings IMECE - International Mechanical Engineering Congress and Exposition, Anaheim, CA, USA, Paper 60669 (2004).

[19] C.J.L. Hermes, C. Melo, F.T. Knabben, J.M. Gonçalves, Prediction of the energy consumption of household refrigerators and freezers via steady-state simulation, International Journal of Applied Energy 86 (2009) 1311-1319.

[20] IBM, IBM BladeCenter: Build Smarter IT Retrieved 09:30, May 20, 2011, (2010) Available from: ftp://public.dhe.ibm.com/common/ssi/ecm/en/blb03002usen/ BLB03002USEN.PDF.

[21] J. Ishimine, Y. Ohba, S. Ikeda, M. Suzuki, Improving IDC cooling and air conditioning efficiency, FUJITSU Scientific \& Technical Journal 45 (2009) 123-133.

[22] J.G. Koomey, Estimating Total Power Consumption by Servers in the U.S. and the World February 15,, Analytics Press, Oakland, CA, 2007, Available from: http://enterprise.amd.com/us-en/AMD-Business/Technology-Home/PowerManagement.aspx.

[23] J.B. Larson, America's Energy Security Trust Fund Act of 2009 (2009) H.R. 1337.

[24] J. Lee, I. Mudawar, Low-Temperature two-phase microchannel cooling for high-Heat-Flux thermal Management of Defense electronics, IEEE Transactions on Components and Packaging Technologies 32 (2) (2009) 453-465.

[25] P.L. Leonard, A.L. Phillips, The Thermal Bus Opportunity - A Quantum Leap in Data Center Cooling Potential, ASHRAE Transactions, Denver, CO, 2005.

[26] D. Liu, S. Wang, Flow pattern and pressure drop of upward two-phase flow in vertical capillaries, Industrial and Engineering Chemistry Research 47 (2008) 243-255.

[27] Y. Madhour, J.A. Olivier, E. Costa-Patry, S. Paredes, B. Michel, J.R. Thome, Flow Boiling of R134a in a Multi-Microchannel Heat Sink with Hotspot Heaters for Energy-Efficient Microelectronic CPU Cooling Applications, IEEE Transactions on Components, Packaging and Manufacturing Technology 1 (6) (2011) $873-883$.

[28] Marcinichen, J.B., Thome, J.R., 2010, "New Novel Green Computer Two-Phase Cooling Cycle: a Model for Its Steady-State Simulation", in Proceedings of the 23rd International Conference on Efficiency, Cost, Optimization, Simulation and Environmental Impact of Energy Systems - ECOS2010, Lausanne, Switzerland.

[29] J.B. Marcinichen, J.R. Thome, B. Michel, Cooling of microprocessors with micro-evaporation: a novel two-phase cooling cycle, International Journal of Refrigeration (2010)

[30] J.B. Marcinichen, J.A. Olivier, V. Oliveira, J.R. Thome, A Review of On-Chip Micro-Evaporation: Experimental Evaluation of Liquid Pumping and Vapor Compression Driven Cooling Systems and Control, International Journal of Applied Energy 92 (2011) 147-161.

[31] A.W. Mauro, J.R. Thome, D. Toto, G.P. Vanoli, Saturated critical heat flux in a multi-microchannel heat sink Fed by a split flow system, Experimental Thermal and Fluid Science 34 (2010) 81-92.

[32] J.P. Meyer, J.A. Olivier, Transitional flow inside enhanced tubes for fully developed and developing flow with different types of inlet disturbances: part II-heat transfer, International Journal of Heat and Mass Transfer 54 (2011) 1598-1607.

[33] R.L. Mitchel, Carbon tax could whack data centers, Computerworld (2010) Available from: http://blogs.computerworld.com/16128/carbon_tax_could_ whack_data_centers|.

[34] Mongia, R., Masahiro, K., DiStefano, E., Barry, J., Chen, W., Izenson, M., Possamai, F., Zimmermann, A. and Mochizuki, M., 2006, "Small scale refrigeration system for electronics cooling within a notebook computer", in Proceedings ITHERM, San Diego, CA.

[35] M.J. Moran, I. Howard, N. Shapiro, Fundamentals of Engineering Thermodynamics, sixth ed. John Wiley \& Sons, 2010, 725 pages.

[36] H. Muller-Steinhagen, K. Heck, A simple pressure drop correlation for twophase flow in pipes, Chemical Engineering and Processing: Process Intensification 20 (1986) 297-308.
[37] W. Nordhaus, A Question of Balance - Weighing the Options of Global Warming Policies, Yale University Press, New Haven, 2008.

[38] Olivier, J.A., Marcinichen, J.B and Thome, J.R., 2010, "Two-phase cooling of datacenters: reduction in energy costs and improved efficiencies", in Proceedings of the 13th Brazilian congress of thermal sciences and engineering - ENCIT2010, Uberlandia, MG, Brazil.

[39] C.L. Ong, J.R. Thome, Macro-to-microchannel transition in two-phase flow: part 2 - flow boiling heat transfer and critical heat flux, Experimental Thermal and Fluid Science (2011). doi:10.1016/j.expthermflusci.2010.12.003.

[40] Park, J.E., 2008. "Critical heat flux in multi-microchannel copper elements with low pressure refrigerants", PhD Thesis, École Polytechnique Fédérale de Lausanne, Switzerland.

[41] J.E. Park, J.R. Thome, Critical heat flux in multi-microchannel copper elements with low pressure refrigerants, International Journal of Heat and Mass Transfer 53 (2010) 110-122.

[42] Perez-Tellez, C., 2003, "Improved bottomhole pressure control for underbalanced drilling operations", Ph.D. Dissertation, Louisiana State University.

[43] T.S. Ravigururajan, A.E. Bergles, General correlations for pressure drop and heat transfer for single-phase turbulent flow in internally ribbed tubes, Augmentation of Heat Transfer in Energy Systems 52 (1985) 9-20.

[44] R. Revellin, J.R. Thome, A theoretical model for the prediction of the critical heat flux in heated microchannels, International Journal of Heat and Mass Transfer 51 (2008) 1216-1225.

[45] G. Ribatski, L. Wojtan, J.R. Thome, An analysis of experimental data and prediction methods for two-phase frictional pressure drop and flow boiling heat transfer in micro-scale channels, Experimental Thermal and Fluid Science 31 (2006) 1-19.

[46] M.A. Rosen, I. Dincer, M. Kanoglu, Role of exergy in increasing efficiency and sustainability and reducing environmental impact, Energy Policy 36 (2008) 128-137.

[47] M. Saini, R.L. Webb, Heat rejection limits of air cooled plane fin heat sinks for computer cooling, IEEE Transactions on Components and Packaging Technologies 26 (1) (2003) 71-79.

[48] E. Samadiani, S. Joshi, F. Mistree, The thermal design of a next generation data center: a conceptual exposition, Journal of Electronic Packing 130 (2008) 041104-41111 041104-041108.

[49] R.R. Schmidt, B.D. Notohardjono, High-end server low-temperature cooling, IBM Journal of Research and Development 46 (2002) 739-751.

[50] P.L. Spedding, E. Benard, G.M. McNally, Fluid flow through 90 degree bends Developments in Chemical Engineering and Mineral Processing 12 (2004) 107-128.

[51] Y. Taitel, D. Bornea, A.E. Dukler, Modelling flow pattern transitions for steady upward gas-liquid flow in vertical tubes, AIChE Journal 26 (3) (1980) $345-355$.

[52] Thome, J.R., Agostini, B., Revellin, R. and Park, J.E., 2007, “Recent advances in thermal modeling of micro-evaporators for cooling of microprocessors", in Proceedings of the ASME International Mechanical engineering Congress and exposition (IMECE), Seattle, Washington.

[53] Thome, J.R. and Bruch, A., 2008, "Refrigerated cooling of microprocessors with micro-evaporation heat sinks: new development and energy Conservation Prospects for green datacenters", in Proceedings Institute of refrigeration (IOR).

[54] J. Thome, V. Dupont, A. Jacobi, Heat transfer model for evaporation in microchannels. Part I: presentation of the model, International Journal of Heat and Mass Transfer 47 (2004) 3375-3385.

[55] S. Trutassanawin, E.A. Groll, S.V. Garimella, L. Cremaschi, Experimental investigation of a miniature-scale refrigeration system for electronics cooling, IEEE Transactions on Components and Packaging Technologies 29 (3) (2006) 678-687.

[56] S. Voss, G. Gould, The Rankine Cycle: Workhorse of the Coal-fired Utility Industry, TechBriefs, Burns \& McDonnell, 2001, No 3, pp. 4-6.

[57] World_Coal_Association, Coal \& Electricity (2011) Available from: http:// www.worldcoal.org/coal/uses-of-coal/coal-electricity/.

[58] R. Zhou, T. Zhang, J. Catano, J.T. Wen, G.J. Michna, Y. Peles, M.K. Jensen, The steady-state modeling and optimization of a refrigeration system for high heat flux removal, Applied Thermal Engineering (2010). doi:10.1016 j.applthermaleng.2010.05.023. 